\title{
Mechanism of preferential complex formation by Apoptosis Signal-regulating Kinases.
}

Sarah J. Trevelyan ${ }^{1}$, Jodi L. Brewster ${ }^{1}$, Abigail E. Burgess' ${ }^{1}$, Jennifer M. Crowther ${ }^{2}$, Antonia L. Cadell ${ }^{3}$, Benjamin L. Parker ${ }^{4}$, David R. Croucher ${ }^{3,5,6}$, Renwick C.J. Dobson ${ }^{2,7}$, James M. Murphy ${ }^{8,9}$, Peter D. Mace ${ }^{1, a}$

1. Biochemistry Department, School of Biomedical Sciences, University of Otago, P.O. Box 56, 710 Cumberland St., Dunedin 9054, New Zealand

2. Biomolecular Interaction Centre, School of Biological Sciences, University of Canterbury, Christchurch, New Zealand

3. The Kinghorn Cancer Centre, Garvan Institute of Medical Research, Sydney, New South Wales 2010, Australia

4.Department of Physiology, School of Biomedical Sciences, The University of Melbourne, Parkville, Victoria 3010, Australia

5. St Vincent's Hospital Clinical School, University of New South Wales, Sydney, New South Wales, 2052, Australia

6. School of Medicine and Medical Science, University College Dublin, Belfield, Dublin 4, Ireland

7. Department of Biochemistry and Molecular Biology, Bio21 Molecular Science and

Biotechnology Institute, University of Melbourne, Parkville, Victoria 3010, Australia

8. The Walter and Eliza Hall Institute of Medical Research, Parkville, Victoria 3052, Australia

9. Department of Medical Biology, University of Melbourne, Parkville, Victoria 3010, Australia

a. To whom correspondence may be addressed. Email: peter.mace@otago.ac.nz 


\begin{abstract}
Apoptosis signal-regulating kinases (ASK1-3) are activators of the P38 and JNK MAP kinase pathways. ASK1-3 form oligomeric complexes known as ASK signalosomes that initiate signalling cascades in response to diverse stress stimuli. Here we demonstrate that oligomerization of ASK proteins is driven by previously uncharacterised sterile-alpha motif (SAM) domains that reside at the C-terminus of each ASK protein. SAM domains from ASK1-3 have distinct behaviours: ASK1 forms unstable oligomers, ASK2 is predominantly monomeric, and the ASK3 SAM domain forms a stable oligomer even at low concentration. In contrast to their isolated behaviour, the ASK1 and ASK2 SAM domains preferentially form a stable heterocomplex. The crystal structure of the ASK3 SAM domain, small-angle X-ray scattering, and mutagenesis suggests that ASK3 oligomers and ASK1-ASK2 complexes form discrete quasi-helical rings, via the mid-loop-end-helix interface. Preferential ASK1ASK2 binding is consistent with mass spectrometry showing that full-length ASK1 forms heterooligomeric complexes incorporating high levels of ASK2. Accordingly, disruption of SAM domain-association impairs ASK activity in the context of electrophilic stress induced by 4-hydroxy-2-nonenal. These findings provide a structural template for how ASK proteins assemble foci to drive inflammatory signalling, and reinforce that strategies targeting ASK kinases should consider the concerted actions of multiple ASK family members.
\end{abstract}




\section{Introduction}

Mitogen-activated protein kinase (MAPK) cascades are ubiquitous in eukaryotes as a means of sensing and responding to stressors. In humans, the JNK and P38 MAP kinases are activated by upstream MAP kinase kinases (MAP2Ks), which are in-turn activated by a diverse group of MAP3Ks. Although the activation of both MAPKs and MAP2Ks by phosphorylation is well understood, MAP3Ks are less well characterised. This imbalance likely stems from the fact that while MAPKs and MAP2Ks are activated by relatively welldefined upstream kinases, stress-activated MAP3Ks must recognise and respond to a wide range of stressors so have more diverse regulation that remains to be characterised at the molecular level.

Apoptosis signal-regulated kinases (ASKs) are a group of MAP3Ks that respond to a broad variety of chemical, physical and inflammatory stimuli. In humans there are three ASK-family kinases (ASK1-3; MAP3K5, MAP3K6 and MAP3K15, respectively). ASK1 has been intensively studied following the initial discovery of its activation in response to TNFa, promoting cell death (1). Subsequently, roles for all three ASK kinases have been defined in various biological pathways and disease states. For instance, ASK1 is now well established in the response to oxidative stress and inflammatory cytokines (2, 3). ASK1 and ASK2 are required for effective responses to viral infection (4-6), to prime NLR inflammasomes following challenge by bacterial infection (7), and together act to mediate neutrophillic dermatitis (8). In simplified terms, it appears that ASK1 and ASK2 in isolation are each able to promote some level of P38/JNK activation and stress response, but their concerted action generates a broader inflammatory response, and cell death. ASK3 apparently has a more specialised role in sensing and responding to osmotic pressure and regulation of blood pressure, specifically in the kidney via the WNK1 pathway (9).

Recently, ASK1 has generated significant interest due to the relevance of ASK1 to disease and the availability of specific inhibitors, in particular Selonsertib (10). Activating mutations of ASK1 occur in melanoma (11), and inhibition of ASK1 has shown benefit in gastric cancers $(12,13)$. Most notably, ASK1 is a relevant target in non-alcoholic steatohepatitis (NASH; (14)). ASK1 inhibition with Selonsertib has shown promising results up to phase two clinical trials (10), and inhibitors derived from Selonsertib also reduce fibrosis caused by kidney inflammation (15). Despite their clinical relevance, a structural understanding of ASK protein complexes beyond the well-conserved catalytic kinase domain is limited. The ASK1 kinase domain structure was first solved in 2007 (16), and subsequently crystal structures of small-molecule inhibitors in complex with the kinase have become available. However, 
ASK1-3 are each greater than 1300 amino acids in length and the precise mechanisms linking their conserved architecture-where the central kinase domain is flanked by large $\mathrm{N}$ and $\mathrm{C}$-terminal regulatory domains (Figure $1 \mathrm{~A}$ ) — to kinase activity remain unclear.

The current model of ASK1 regulation invokes constitutive oligomerisation mediated through the C-terminal region, in parallel with stimuli-dependent regulation of ASK signalling via the $\mathrm{N}$-terminus (17). Many of the signalling molecules that are proposed to regulate stressinduced activation of ASK1 interact via its N-terminal domains. There are further outstanding questions regarding the interaction of regulatory and oligomerising domains of ASK proteins. It is not clear if regulation of substrate recruitment and priming, through a domain just $\mathrm{N}$ terminal to the kinase (18), occur in an intra- or inter-molecular manner. Likewise it is not known if dimers reported for the isolated kinase domain of ASK1 impact kinase function in the context of full-length protein (16). Moreover, the C-terminal region of ASK proteins is clearly important for signalosome formation and activity, but the structural mechanism of assembly and how this relates to oligomerisation of different ASK-type kinases remains to be determined.

Here we present the crystal structure of the C-terminal domain of ASK3, which adopts a sterile alpha motif-a fold classically shown to mediate protein-protein interactions that had not previously been described in ASK proteins. Interrogating the behaviour of C-terminal domains of ASK1-3 using a variety of methods in solution and full length ASK1/2 in cells uncovers distinct behaviours of the C-terminal domains from the three ASK proteins, which impact protein complex assembly and activity. This data provides a structural basis for previous observations regarding ASK protein oligomerisation, and functional cooperativity of ASK proteins in a variety of biological settings. 


\section{Results}

\section{ASK1-3 C-terminal domains have divergent oligomerisation propensities}

Sequences C-terminal to the ASK1 kinase domain are known to play roles in binding regulatory proteins $(19,20)$, and facilitating interactions between ASK proteins to generate oligomeric ASK signalosomes (17). While a coiled-coil region is predicted near the Cterminus of each ASK protein, the precise structural architecture of the C-terminal portion of ASK proteins is unclear. To gain insight into the mechanism of oligomerisation, we expressed C-terminal fragments from ASK1, ASK2, and ASK3. Regions of ASK1(10391374), ASK1(1237-1374), ASK2(988-1288), and ASK2(1156-1288) that incorporate the predicted C-terminal coiled-coil (residues 1245-1285 in ASK1) were all highly insoluble when expressed alone or co-expressed, in either E. coli or Sf9 insect cells. In contrast, shorter constructs comprising ASK1(1290-1374), ASK2(1216-1288) and ASK3(12411313) $(9.8,8.2,8.5 \mathrm{kDa}$, respectively) all readily expressed in a soluble form in $E$. coli.

Assessment of the soluble C-terminal portions of ASK proteins using analytical sizeexclusion chromatography (SEC) and analytical ultracentrifugation (AUC) revealed that these smaller fragments themselves had the ability to form oligomers. However, each exhibited a distinct behaviour. SEC showed an unstable ASK1 oligomer that existed in an equilibrium between multiple oligomeric states, even at concentrations as high as $200 \mu \mathrm{M}$ (Figure 1B). Sedimentation velocity AUC corroborated this result, whereby between 15-150 $\mu \mathrm{M}$ ASK1 formed concentration-dependent oligomers of two distinct sizes (Figure 1C; Supp. Table 1). In comparison, ASK2 was a single species on SEC, eluting with an apparent mass consistent with a monomer (Figure 1B). AUC also showed that the ASK2 exists almost exclusively as a monomer, only exhibiting a minor dimer species when analysed at a concentration of $365 \mu \mathrm{M}(3 \mathrm{mg} / \mathrm{mL})$. Finally, ASK3 forms a large and stable oligomer, with an apparent mass of $\sim 54 \mathrm{kDa}$ assessed from molecular weight standards (Figure 1B). Analysis of ASK3 using AUC suggested a single oligomeric state over a 10-fold concentration range (Figure 1C; Supp. Table 1), allowing for a good mass estimation from the sedimentation velocity experiment. When measured between 0.15 and $1.5 \mathrm{mg} / \mathrm{mL}$, the calculated molecular weight values fell in a range between 41.3 and $47 \mathrm{kDa}$, generally between the mass of an ASK3 pentamer or hexamer, which would have a theoretical mass of $\sim 42.5 \mathrm{kDa}$ or $51 \mathrm{kDa}$ respectively. 
To further interrogate the soluble C-terminal domains of ASK1-3 we analysed their primary sequences using sequence profile matching (21), which suggested significant homology to sterile-alpha motif (SAM) domains from various proteins-including P63, Tankyrase, and yeast MAPK-related proteins Ste11 and Ste50 (22-25). While there has been some reference to a predicted SAM domain in ASK1 (26), the SAM designation does not appear in major fold-prediction databases, and the same region has also been noted to

A

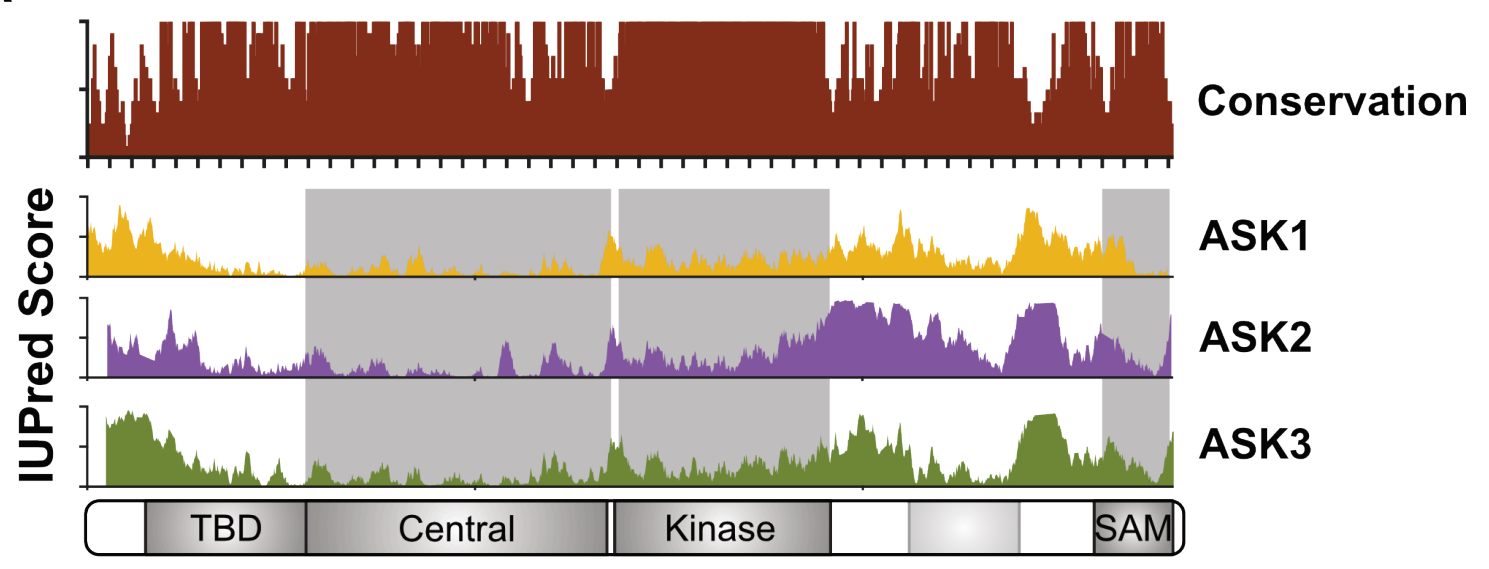

B
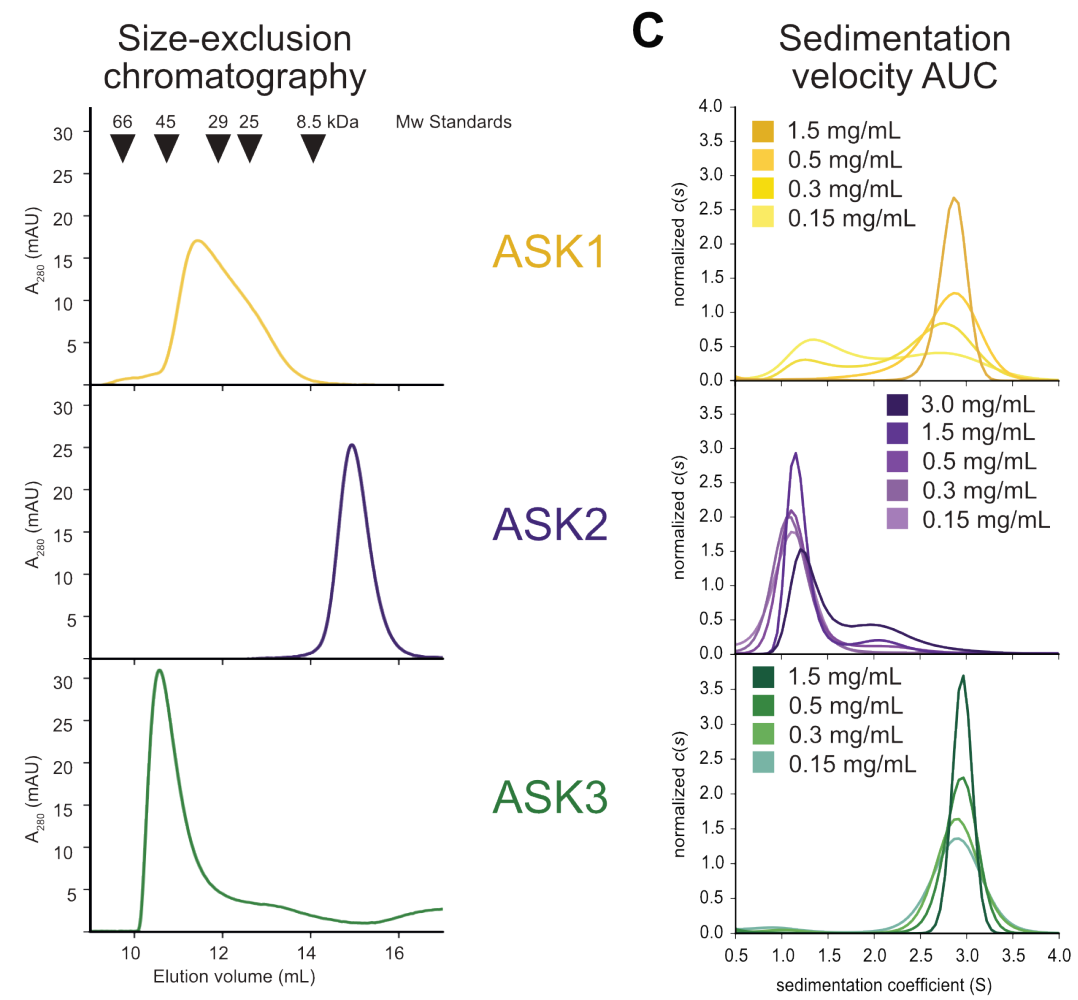

Figure 1: ASK1, ASK2 and ASK3 C-terminal domains have different oligomerisation propensity. (A) Overview of domain architecture, and conservation of ASK1-3. (B) Size-exclusion chromatography of ASK1(1290-1374), ASK2(1216-1288) and ASK3(1241-1313), corresponding to regions of respective ASK proteins labelled 'SAM' domain in panel $A$. (C) Sedimentation velocity AUC analysis of ASK1, 2 and 3 domains at indicated concentrations spanning between 0.15 and 3.0 $\mathrm{mg} / \mathrm{mL}(15-365 \mu \mathrm{M})$. 
contain a ubiquitin-like sequence motif $(26,27)$. Because SAM domains are versatile interaction modules that mediate both protein-protein and protein-DNA interactions, a Cterminal SAM domain would make an ideal candidate to mediate ASK oligomer formation.

\section{The ASK3 C-terminal domain is a Sterile-Alpha Motif (SAM) domain}

To gain further insight into the oligomerisation mechanism of the ASK1-3 C-terminal domains we pursued structural studies. Crystallisation trials of the soluble C-terminal domains from the three ASK proteins yielded crystals of ASK3(1241-1313), from which the structure was solved using a combination of SIRAS and MR-SAD (see methods; Figure 2A). The structure was refined against native diffraction data to a resolution of $1.8 \AA$, and has excellent geometric parameters (Table 1). There are three molecules of ASK3(1241-1313) in the asymmetric unit; with the ASK3 polypeptide chain defined from residues 1241-1308 in two molecules, and 1241-1305 in the remaining molecule.

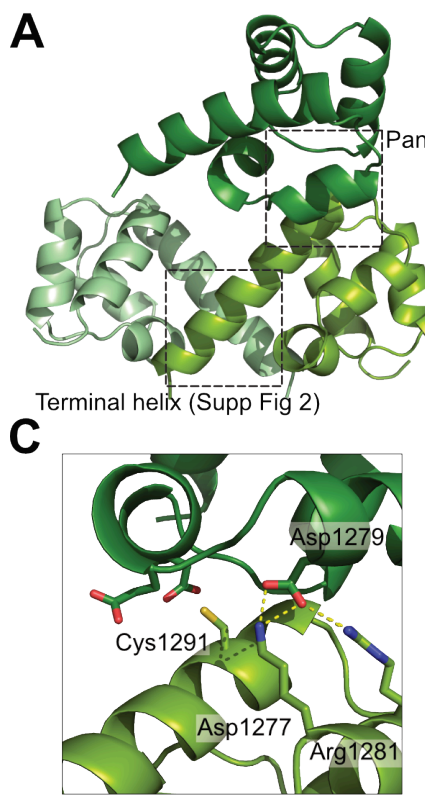

B
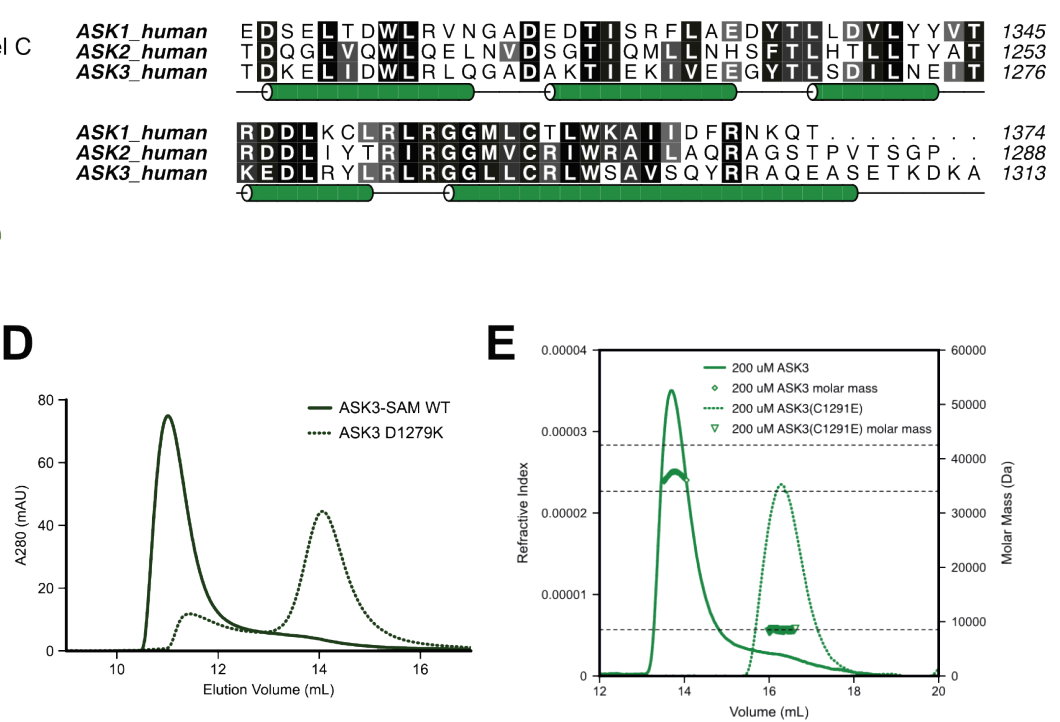

Figure 2: Structure of the ASK3 SAM domain. (A) Cartoon representation of the crystal structure of ASK3(1290-1374) displaying the three monomers within the asymmetric unit. The ML-EH interface is indicated with a dashed box. (B) Alignment of SAM domains of human ASK1-3. (C) Close-up view of wild-type residues within the dashed areas of the ML-EH interface. (D) Sizeexclusion chromatography trace indicating the disruption of the wild-type ASK3-SAM oligomer as a result of a aspartate to lysine mutation at position 1279 (ASK3(D1279K)). (E) SEC-MALS data measuring the molar mass of a cysteine to glutamate mutant at position 1291 (ASK3(C1291E)), relative to the wild-type oligomer.

Consistent with bioinformatic prediction, the C-terminal domain of ASK3 adopts the classical five-helix fold of the sterile-alpha motif domain (SAM). The sequence of ASK1 and ASK2 are 53 and $37 \%$ identical in the equivalent regions to the solved structure of ASK3 
(Figure 2B). The highest levels of conservation are concentrated in hydrophobic core residues, and both ASK1 and ASK2 are also predicted to contain five helices. Therefore, we propose that the three ASK proteins all possess a similar SAM-fold at their C-terminus. Although we grew crystals of the SAM domain of ASK1, the crystals did not diffract sufficiently for structure determination.

\section{Oligomer formation by the ASK3 SAM domain}

With three ASK3 molecules in the asymmetric unit, there are several interfaces through which ASK oligomers may form. Based on the crystal contacts, we observed three possibilities (Supp. Fig. 1): the mid-loop:end-helix (ML-EH) interaction that has been observed for SAM domains from diverse protein families (Figure $2 \mathrm{~A} / \mathrm{C}$ ); a symmetrical interaction formed by the C-terminal helix of ASK3, and a symmetrical interaction though the surface of $\alpha 1$ and $\alpha 2$ with a neighbouring asymmetric unit. We generated a suite of mutant ASK3 SAM domains to deduce which of the interfaces observed in the crystal lattice corresponds to the oligomerisation interface in solution. Examining mutants by sizeexclusion chromatography, we identified the ML-EH interaction as the crucial site for oligomerisation. Strikingly, the (ML-EH) mutant D1279Q eluted with an apparent mass of 13 $\mathrm{kDa}$, close to that of a monomer (Figure 2C/D). Mutation of residues at the C-terminal helix led to ambiguous results: ASK3 Y1300Q caused a shift towards smaller apparent mass of $22 \mathrm{kDa}$, and Q1304A did not affect the wild-type ASK3 SAM oligomer (Supp. Fig. 2). The $\mathrm{V} 1262 \mathrm{~N}$ and K1242E mutants at the $\alpha 1 / \alpha 2$ interface did not disrupt the oligomer (Supp. Fig. 2 ), indicative of purely crystallographic contacts through $\alpha 1 / \alpha 2$. Thus, we cannot completely discount the role of the C-terminal-helix interaction, but the ML-EH interaction is indispensible for ASK3 oligomer formation and a single point mutant at this interface most effectively disrupts the ASK3 complex. While there is some possibility of a C-terminal interaction ASK3, we can effectively exclude such an interaction for ASK1 based on several criteria: an equivalent ASK1 mutation (F1369Q) behaves in an identical manner to WT protein (Supp. Fig. 3A); ASK1 has a truncated C-terminal helix relative to ASK3 that would disrupt half of the interacting surface (Supp. Fig. 3B); and two ASK3 residues from a3 that pack against the C-terminal helix (Ser1269 and Asn1273) are not conserved in ASK1 (Supp. Fig. 3B).

To further probe the role of the ML-EH interface in ASK interactions, we created an additional mutation on the opposite side of the interface in both ASK3(C1291E) and ASK1(C1360E), and used SEC-MALS to test their ability to oligomerise. Consistent with an indispensable role for the ML-EH interface, ASK3(C1291E) had a calculated mass of 8.5 kDa (Figure 2E), and ASK1(C1360E) had a calculated mass of 13.4 kDa (Supp. Fig. 3C). 
The wild-type ASK2 SAM domain had a calculated mass of $8.6 \mathrm{kDa}$ in SEC-MALS, even though it eluted in a notably different position relative to ASK1/ASK3 monomers (Supp. Fig. 3). This may indicate that ASK2 has more compact monomeric hydrodynamic radius and/or different flexibility at the C-terminal tail relative to ASK1 and ASK3.

From these data, we conclude that weak oligomerisation of the ASK1 SAM domain and stable oligomer formation by the ASK3 SAM domain requires the ML-EH interface, because single point mutants that disrupt the ML-EH behave as a monomeric proteins.

\section{ASK1-ASK2 form heterotypic complexes via the ML-EH interface}

ASK1 and ASK2 have previously been reported to associate through their C-terminal domains (4), and endogenous ASK1 and ASK2 have been reported to exist in complex with one another at an equal ratio (28). We next sought to test whether such heterotypic association could be driven through the isolated SAM domains of each ASK protein. As an initial measure, we prepared GST-fused forms of the SAM domain from each ASK protein, and tested the ability of each to pulldown the other respective SAM domains (Figure 3A). Strikingly, we observed that ASK1 SAM domain clearly only associated with the ASK2

A

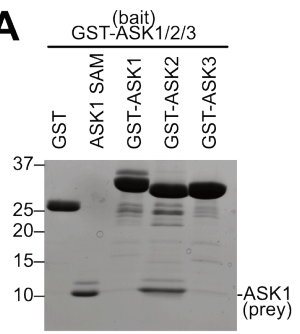

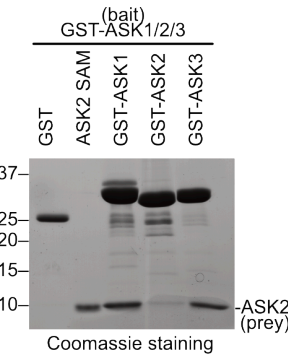

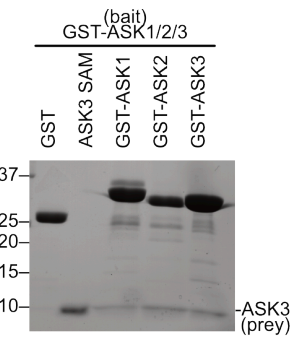

D

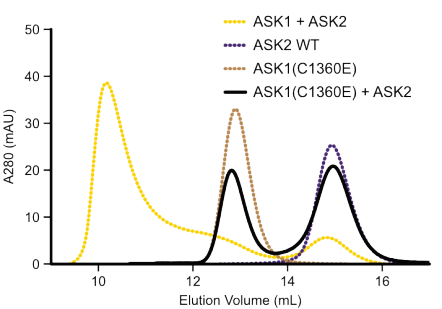

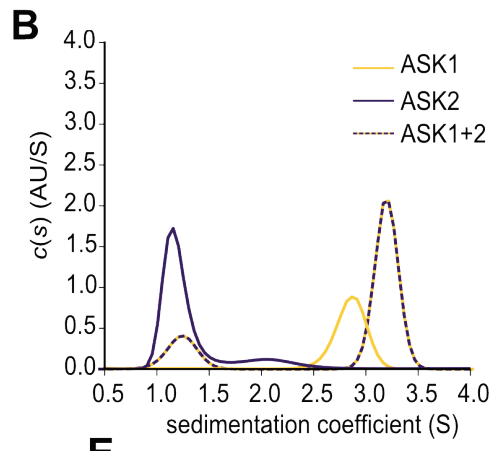

E

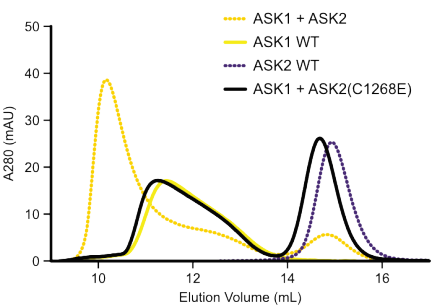

Figure 3: Heterotypic interactions between ASK SAM domains (A) GST-pulldown experiments measuring the ability of GST-ASK1, -ASK2, and -ASK3 SAM domains to pull down untagged SAM domains from ASK1, ASK2 and ASK3 respectively (B) Sedimentation velocity analytical ultracentrifugation of the isolated SAM domains of ASK1, ASK2 $(1.5 \mathrm{mg} / \mathrm{mL})$ and an equimolar mixture of the two (at $1.5 \mathrm{mg} / \mathrm{mL}$ each). (C) GST-pulldown experiments measuring the ability of WT GST-ASK1 and GST-ASK2 SAM domains to pull down either WT, or Cysteine mutant ASK1 and ASK2 SAM domains. (D) Analytical size-exclusion chromatography comparing the ability of WT and C1360E ASK1 SAM domain to form a higher-order oligomer with the WT ASK2 SAM domain. (E) Analytical size-exclusion chromatography comparing the ability of WT and C1268E ASK2 SAM domain to form a higher-order oligomer with the WT ASK1 SAM domain. 
domain, but not untagged ASK1, or ASK3 SAM. The ASK2 SAM domain was not able to pull down its own untagged form-consistent with its monomeric behaviour in solution (Figure 1B/C; Supp. Table 1)—but could readily pull down ASK1 and ASK3 (Figure 3A). ASK3 on the hand showed only weak interactions with untagged SAM domains from any ASK protein (Figure 3A). The scarcity of interactions by ASK3 could be because ASK3 readily forms oligomers over a range of concentrations (Figure 1C), and thus GST-ASK3 SAM is unable to incorporate further untagged ASK3 SAM.

To further characterise the heterotypic association of ASK1-ASK2 we used sedimentation velocity AUC (Figure 3B; Supp. Table 1). Consistent with GST-pulldowns, the ASK1-ASK2 mixture readily associated, and formed a defined oligomer. Such behaviour is in marked contrast to the weak homotypic association of ASK1 and ASK2 SAM domains, and suggests that the two domains from ASK1 and ASK2 preferentially oligomerize into a larger complex. This behaviour suggests that the SAM domains of each protein contribute markedly to the heterotypic ASK1-ASK2 complexes previously reported $(4-8,28)$.

To ascertain if ASK1-ASK2 hetero-oligomers also use the ML-EH interface, we first tested the role of the conserved cysteine residue, previously shown to be essential for ASK3 oligomerisation and for weak ASK1 oligomerisation. GST-pulldown experiments clearly showed that mutating either Cys 1360 of ASK1, or Cys1268 of ASK2 to glutamate ablated binding to the WT form of its partner protein (Figure $3 \mathrm{C}$ ). To gain further information on the oligomerisation status of these mutant proteins we performed analytical-SEC (Figure 3D/E). We observed that ASK1(C1360E) showed no higher order complex formation when combined with WT ASK2 SAM domain, having precisely the equivalent elution time as when it was analysed by itself. The corresponding mutation in ASK2(C1268E) reinforced this observation, with the mixture of ASK1-ASK2(C1268E) SAM domains barely distinguishable from their isolated elution positions, showing no sign of higher-order complex assembly. Together, these interaction studies show that the SAM domains from ASK1 and ASK2 exhibit a preference to form heterotypic, rather than homotypic, higher-order oligomers through the ML-EH interfaces of each protein.

\section{SAM-mediated oligomers regulate activity and stoichiometry in cells}

Having established that disrupting the ML-EH interface of either ASK1 and ASK2 abrogates SAM domain heterocomplexes, we sought to test the effects on activity. We transfected wild-type full-length, and disruptive mutations ASK1(C1360E) and ASK2(C1268E), into HEK293FT cells and challenged cells with the prototypic electrophilic 
stress 4-hydroxy-2-nonenal (HNE). As expected, HNE treatment of cells overexpressing wild-type full-length ASK1 induced significant phosphorylation of ASK1, indicating activation of kinase activity. The oligomer disrupted mutant ASK1(C1360E) showed decreased relative phosphorylation upon HNE stimulation, characteristic of impaired activity (Figure 4A/B). When transfected together, wild-type ASK1 and ASK2 show significantly lower basal levels of kinase activity, which is nonetheless activated by HNE. Based on the complete lack of signal in cells transfected with ASK2 alone (WT or C1268E; Figure 4A/B central lanes), the phospho-ASK signal is specific to ASK1, rather than cross-reactivity of the ASK1-

A

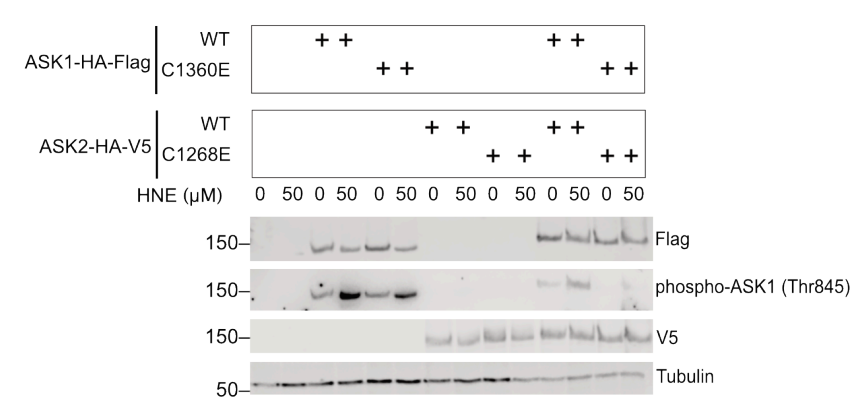

C

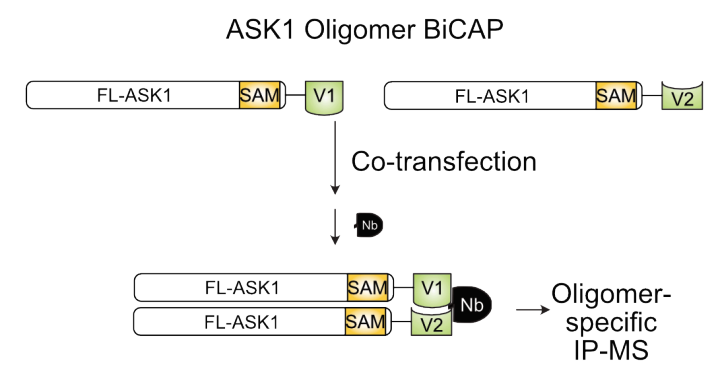

D

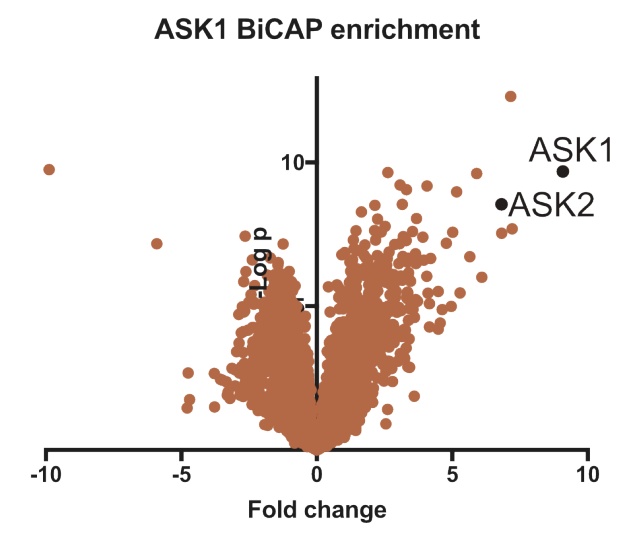

B

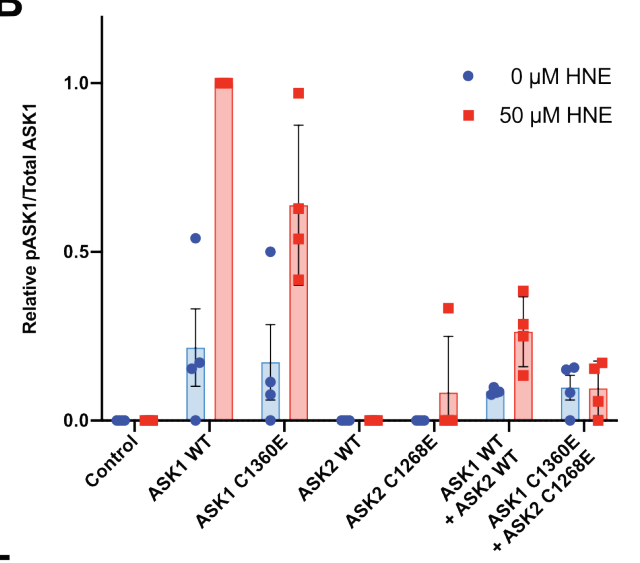

$\mathbf{E}$

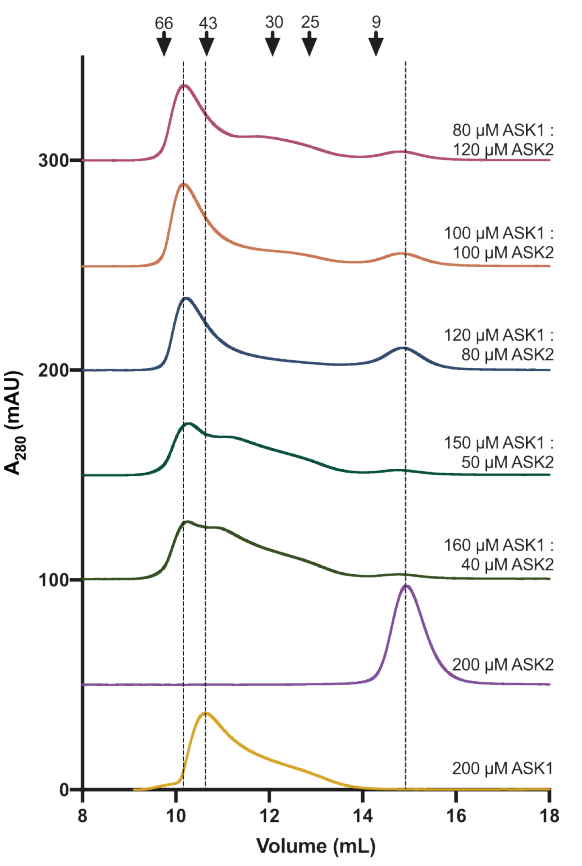

Figure 4: Role of the ML-EH interface in ASK signaling and stoichiometry (A) Analysis of HEK293 cells transfected with indicated constructs, either unchallenged or challenged with HNE (50 $\mu M)$ for 1 hour. (B) Quantitation of the ratio between total ASK1 (assessed via Flag immunoblotting in Panel A) and phospho-Thr845 ASK1, four independent biological replicates. (C) Schematic illustration of the BiCAP system as applied to ASK1. (D) Waterfall plot of BiCAP MS/MS data following anti-GFP nanobody immunoprecipitation. Data is expressed as the fold-change over abundance calculated from a GFP only-transfected cell line treated in an equivalent manner control. (E) Analytical size-exclusion chromatography of mixtures containing indicated concentrations of the ASK1 and ASK2 SAM domains. 
phosphoT845 antibody. A plausible explanation for this observation is ASK1 in complex with ASK2 favours transphosphorylation (4), and therefore limits ASK1 autophosphorylation. Strikingly, transfection of ASK1(C1360E) and ASK2(C1268E) together leads to complete abrogation of basal phosphorylation, which is not stimulated by HNE treatment (Figure 4A/B). From these experiments, we conclude that oligomerisation of ASK proteins through their SAM domains is a core component of active signaling complex formation, which can be disrupted by single point mutations at their ML-EH interfaces.

Elegant endogenous mass spectrometry studies have previously shown that ASK1 associates with near-stoichiometric amounts of ASK2 (28). We employed an orthogonal approach—bimolecular complementation affinity purification $(\operatorname{BiCAP}(29,30))$ - to determine if stoichiometric association of ASK1-ASK2 occurs as part of larger hetero-oligomeric complex. For this system, we created two constructs of full-length ASK1 fused to the Nterminal (V1), and C-terminal (V2), portions of Venus fluorescent protein employed in BiCAP. As such, complexes immunoprecipitated using an anti-GFP nanobody must contain at least two molecules of full-length ASK1 (Figure 4C), rather than associating with any monomeric form of the protein, as may occur with a conventional immunoprecipitation. Partner proteins identified with multimeric ASK1 were identified by mass spectrometry. Remarkably, ASK2 was identified at an abundance of approximately $75 \%$ of ASK1 itself (Figure 4D; Supp. Table 2), even though ASK1 was overexpressed whilst ASK2 was expressed at endogenous levels. Such a result strongly suggests a selective incorporation of near-equal ratios of ASK1 and ASK2 into higher order ASK complexes. Also of note, ASK3 was also enriched in BiCAP analysis, as were several members of the ubiquitin ligase machinery (FbxW11, UBE2N/Ubc13). ASK proteins have previously been shown to undergo regulatory ubiquitination $(20,31,32)$.

Finally, to ascertain whether near equal ASK1-ASK2 stoichiometry observed in cells is recapitulated by isolated SAM domains we completed a series of analytical size-exclusion chromatography experiments with different ratios of ASK1 and ASK2 SAM domains. In these experiments, near equal ratios of ASK1 and ASK2 SAM domains (120:80, 100:100 $\mu \mathrm{M}$ ASK1:ASK2) led to the most homogenous higher order complexes, from a range ratios tested (Figure 4E; 200:0, 160:40, 150:50, 120:80, 100:100, 80:120, 0:200 M, ASK1:ASK2, respectively). Together, these results suggest that SAM domains are a major determinant of ASK oligomeric state, promoting higher order complexes with near equal ratios of ASK1 to ASK2, that can be disrupted to decrease kinase activity in cells. 


\section{Comparison of ML-EH surfaces in ASK paralogs}

The ML-EH interaction occurs in several SAM domain complexes, including both discrete heterodimeric interactions and polymeric arrays of SAM domains. To name contrasting examples: CNK:HYP, and EPH:SHIP2 SAM domains that form a heterodimer pairs $(33,34)$; or poly-ADP-ribosyltransferases Tankyrase (TNKS), ANKS3, and DAG kinase SAM domains, which form left-handed helical filaments through extended ML-EH interactions $(23,24,35,36)$. Using the SSM server to compare structures showed that the ASK3 SAM domain aligns well (RMSD 1.4-2) with a range of the aforementioned SAM domains (Supp. Fig. 4). In order to understand the different oligomerisation propensity within ASK1-3 SAM domains, we compared sequence conservation and electrostatic potential of their $\mathrm{ML}$ and $\mathrm{EH}$ surfaces. A clear pattern emerges when modelling the ASK1 and ASK2 SAM domains based on ASK3 and mapping surface electrostatics (Figure 5A). The ASK3

A
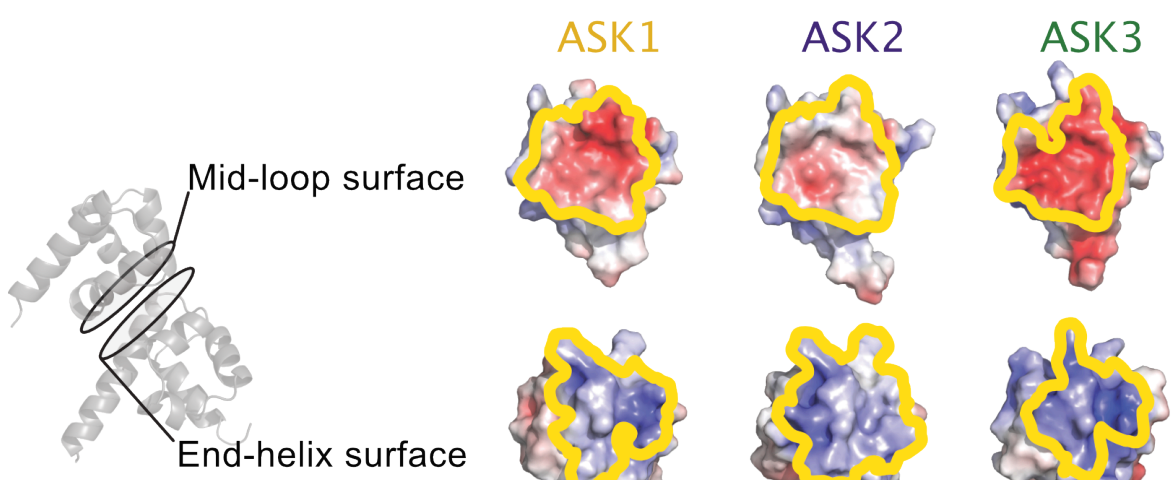

B
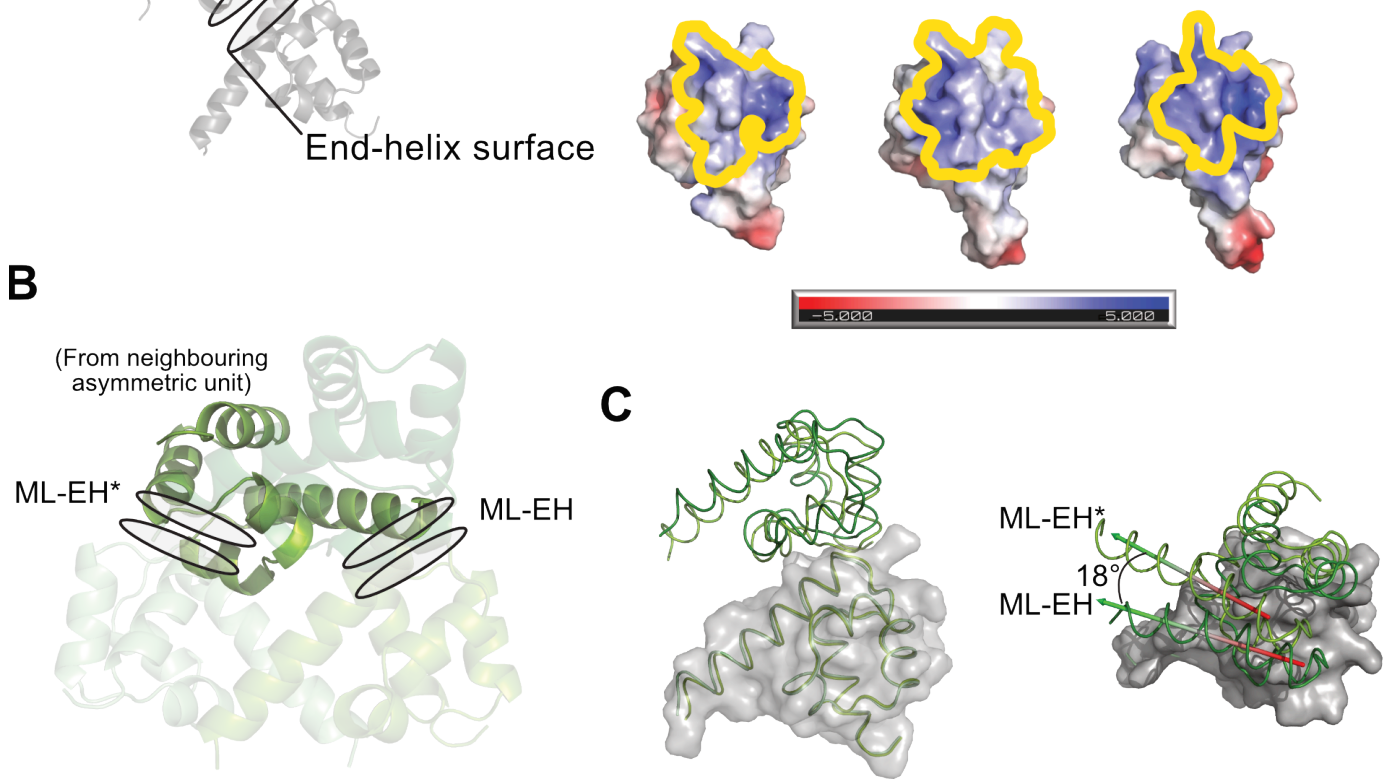

Figure 5: The ASK SAM domain ML-EH interface (A) Left: Schematic view of the ML-EH interface. Right: Electrostatic surfaces of ASK1-3 SAM domains (as calculated using APBS (37), with regions predicted to participate in ML-EH contacts outlined in yellow. Models of ASK1 and ASK2 were generated using MODELLER, based on the ASK3 SAM domain solved here. (B) Illustration of the ML-EH interface seen within the ASK3 asymmetric unit (ML-EH) and the similar but slightly offset arrangement with a crystallographically related SAM domain (ML-EH*) (C) Comparison of the ML-EH and ML-EH* interfaces. Pairs of SAM domains participating in each type of interface overlaid based on the bottom SAM domain. The top SAM domain is offset, quantitated by an $18^{\circ}$ shift of the a5 helix. 
$\mathrm{ML}$ surface is strongly negatively charged and EH surface is strongly positively charged, generating a highly complementary electrostatic interaction. In contrast, the ML surface of ASK2 has a generally hydrophobic character. Paired with a mildly positive EH surface it becomes apparent that the ASK2 ML and EH surfaces are not particularly compatible, hence the ASK2 SAM domain is generally monomeric. Instead, the ASK2 ML surface appears more complementary to the EH surface of the ASK1 SAM domain (Figure 5A), and mildly positive EH surface of ASK1 complementary to the mildly positive charge of the ASK1 ML surface. Such character would explain the observed behaviour of these domains in solution: where homotypic ASK1, or homotypic ASK2, interactions are transient and limited, whereas heterotypic interactions between ASK1/ASK2 surfaces are more complementary, readily leading to stable oligomer formation.

While experiments in cells suggest that the ML-EH surface is crucial to ASK SAM domain function, and surface comparisons provide a basis for selective oligomerisation by ASK SAM domains, an outstanding question remains-why do ASK SAM domains form distinct soluble oligomers, rather than a continuous filamentous structure observed for other SAM domains? For example, mixing high-concentrations of purified monomer/dimer ASK1 and ASK2 SAM domains forms a distinct (non-filamentous) oligomer observed by various measures (Figure 3), and the ASK3 SAM domain also has a defined oligomeric state in solution. In considering this question we further analysed the crystallographic contacts in the ASK3 SAM structure, and observed a second, slightly offset ML-EH interface formed with a SAM domain from a neighbouring asymmetric unit (which we term ML-EH*; (Figure 5B)). The ML-EH* interaction uses effectively identical residues to $\mathrm{ML}-\mathrm{EH}$, but is offset by approximately $18^{\circ}$ when considering the position of the a5 helix (Figure $5 \mathrm{C}$ ). This indicates that there is malleability at the interface that could affect behaviour in solution, in line with other ML-EH complexes and filamentous assemblies.

\section{Solution conformation of ASK SAM oligomers}

To investigate why the ASK SAM domains form higher-order oligomers of defined size we turned to small-angle $X$-ray scattering. We mainly sought to determine whether the SAM domains form an extended helix, or a more compressed helix or ring that may self-limit and give rise to a defined oligomer. In order to estimate experimental and actual scattering of oligomers formed through the ML-EH interface we considered three basic scenarios: oligomers formed by purely the ML-EH interface, purely the $M L-E H^{*}$ interface, or a mixture of the two. Modelling complexes formed through either ML-EH and ML-EH* have markedly different dimensions (Figure 6A), amplifying modest differences in the pairwise interaction 
(Figure 5C). Namely, the pure ML-EH oligomer forms an extended helix with a pitch of $52 \AA$ and 7 units per turn, the purely $\mathrm{ML}-\mathrm{EH}^{*}$ interface a near-symmetrical closed ring, and the
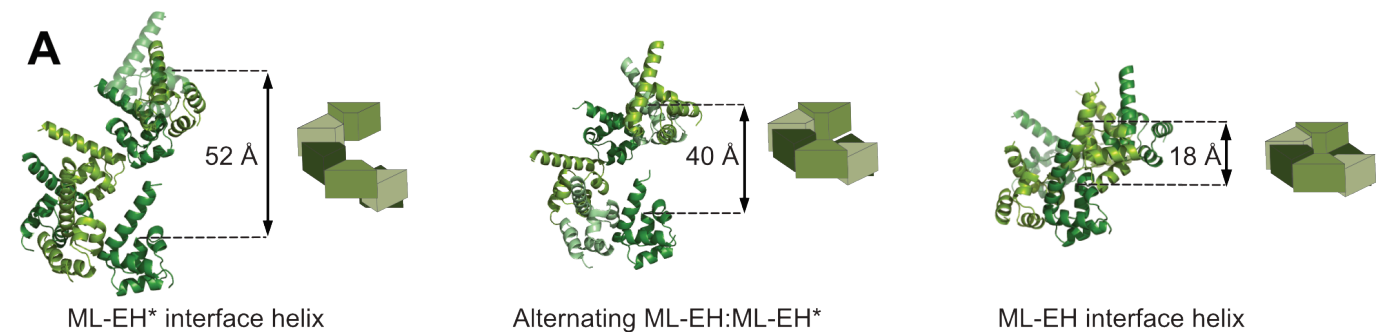

B

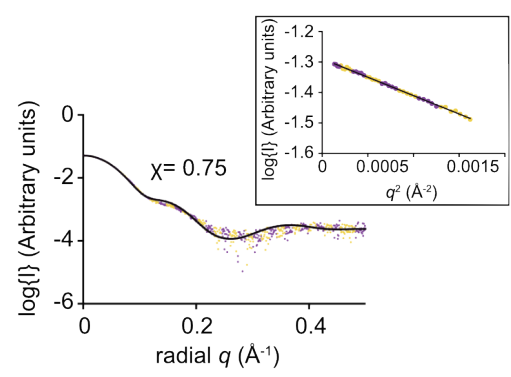

D

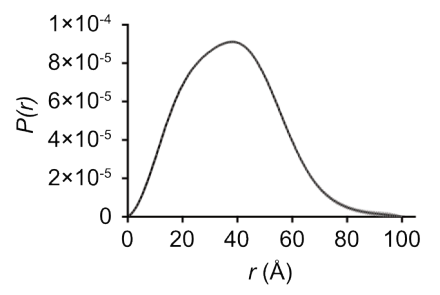

$\mathbf{F}$

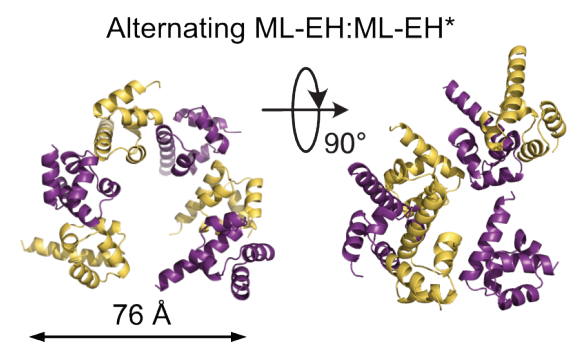

C

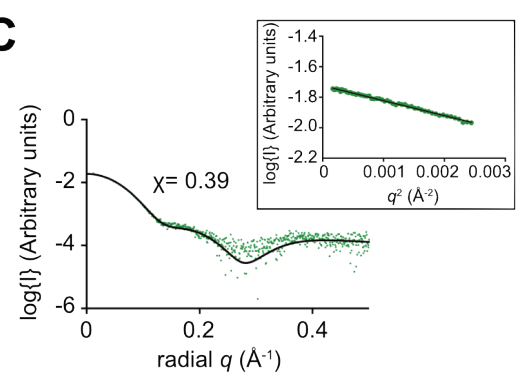

$\mathbf{E}$

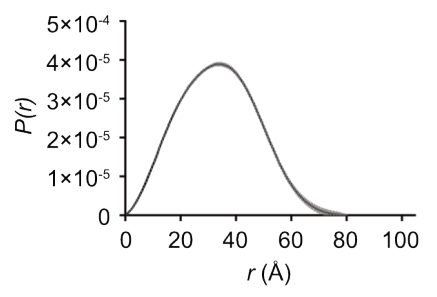

G Repeating ML-EH

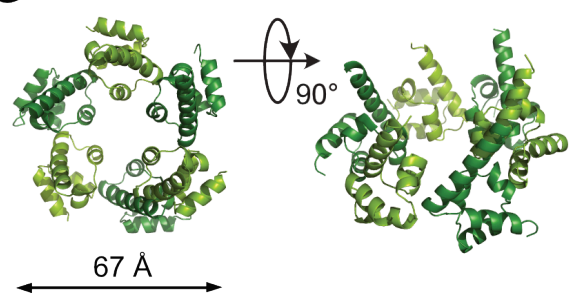

H

\begin{tabular}{clll}
\hline & $\begin{array}{c}\text { ML-EH* interface } \\
\text { hexamer }\end{array}$ & $\begin{array}{c}\text { Alternating ML- } \\
\text { EH:ML-EH* } \mathrm{MLxamer}^{*}\end{array}$ & $\begin{array}{c}\text { ML-EH interface } \\
\text { hexamer }\end{array}$ \\
\hline ASK1+2 SAM & $\mathrm{x}=0.75$ & $\mathrm{x}=0.67$ & $\mathrm{x}=0.97$ \\
ASK3 SAM & $\mathrm{x}=0.96$ & $\mathrm{x}=0.91$ & $\mathrm{x}=0.39$
\end{tabular}

Figure 6: SAXS analysis of ASK1+2 and ASK3 SAM domains. (A)Schematic illustrating the helicies formed from the different $M L-E H$ interfaces seen in the crystal lattice. (B/C) Experimental scattering curves with the best CRYSOL modelled fit (black line) and the Gunier plot (inset) for, ASK1+2 SAM (B); and ASK3 SAM (C). (C/D) Distance distribution plots for, ASK1+2 SAM (D); and ASK3 SAM (E). (F/G) Side and top views of best fit models for the (F) ASK1+2 SAM hexamer (alternating ML$E H / M L-E H^{*}$ ) and (G) ASK3 SAM hexamer (repeated ML-EH; within asymmetric unit). (H)Summary table of the fit of each model to the experimental SAXS data. 
mixed interface an intermediate between the two helices (Figure 6A).

We collected small angle X-ray scattering data for various relevant ASK SAM domains: the isolated ASK1 and ASK2 SAM domains, the ASK1-ASK2 oligomer, and the stable ASK3 SAM domain oligomer (Table 2). Consistent with other in-solution data, the ASK2 SAM scattering data clearly fit a monomeric model ( $\chi=0.60$; Supp. Fig. 5; Supp. Table 3). The experimentally determined scattering profile for ASK1 SAM domain was evaluated against both monomeric and dimeric models, whereby the radius of gyration determined experimentally from the $P(r)$ plot $\left(P(r) R_{g}=14.3\right)$ is most consistent with that of the ML-EH dimer (Supp. Fig. 5;Supp. Table 3). A $P(r) R_{g}$ of 14.3 is intermediate between the theoretical values for the monomer $\left(R_{g}=13.6\right)$ and $\mathrm{MLEH}$ dimer $\left(R_{g}=16.5\right)$, consistent with a mixed population observed in AUC and size-exclusion chromatography (Figure 1; Supp. Table 1).

High quality scattering data was collected for both the ASK1-ASK2 and ASK3 SAM oligomers, with the low $q$ regions of the Guinier plots indicating homogenous, monodisperse protein samples (Figure 6C/F). Several conformational arrangements of pentamer, hexamer and heptamer were tested against experimentally measured scattering using CRYSOL (Supp. Fig. 5; Supp. Table 3; (38)). For all larger complexes the best fits to scattering data were clearly hexameric — clarifying ambiguous estimates of molecular weight arising from SEC-MALS and AUC (Figure 6). When considering flexibility of the ML-EH interface illustrated in Figure 6A, the best fits for ASK1-ASK2 and ASK3 differed. The best fit for the ASK1-ASK2 complex was an intermediate helix formed by a mixture of ML-EH and ML-EH* interfaces $(\chi=0.67)$, whereas ASK3 SAM clearly fit the most compact model tested $(\chi=0.39$; Figure $6 \mathrm{H}$ ). A compact, near-closed ring, for ASK3 is consistent with $D_{\max }$ estimates for ASK3 (80 $\AA$ ), relative to $100 \AA$ for ASK1-ASK2 (Figure 6; Table 2), and provides a clear mechanism for self-limiting oligomerisation. While slightly more extended than ASK3, filament formation by the ASK1-ASK2 complex is likely to be prevented through steric hindrance between neighbouring SAM domains. 


\section{Discussion}

MAP kinase signaling cascades are used throughout eukaryotes to translate external stimuli into cellular responses. Having a three-tiered phosphorylation cascade allows for both signal amplification, and for various levels of regulation. While MAP2K and MAPKs are relatively well conserved, MAP3Ks are significantly more divergent in their domain structure, made necessary by the diverse signals that MAP3Ks sense and respond to-from proliferative signals to signals eliciting cell death. One key mechanism of MAPK regulation is scaffolding of higher order complexes, which tethers relevant proteins into coherent signaling packages (39). Protein scaffolding can also modulate catalytic activity of kinases within MAPK pathways $(40,41)$. ASK kinases in humans are a three-membered sub-family of MAP3Ks, which have long been known to form higher order complexes that are inherent to their function. Here we demonstrate that ASK1-3 contain a previously uncharacterised domain at their extreme C-terminus, in the form of a SAM domain-a prevalent protein-protein interaction domain used throughout Eukaryota (42). The SAM domains from the three ASK orthologs have relatively divergent oligomerisation tendencies, even though they use the same oligomerisation surface as each other and many other SAM domains. The preferred state of ASK1-3 SAM domains varies, but notably does not extend beyond a hexameric state by any of the measures we tested, even at very high protein concentration. Both the formation of discrete oligomers, and preferential hetero-oligomer formation are notable features of ASK SAM domain complex formation.

SAM domains have been characterised as either monomeric or oligomeric (43), with oligomers generally exhibiting either pairwise dimer formation, or filamentous oligomer formation via the ML-EH interface. The relative orientation between ASK3 SAM domains in our crystal structure are comparable to that seen in either discrete or filamentous SAM domain oligomers. This translates to a roughly equivalent putative helical pitch (33-53 $\AA$ ) to that of classical filamentous SAM domains, such as that of Tankyrase, Diacylglycerol kinase and others (Supp. Fig. 6; $(23,24,35,44,45))$. However, within the crystal there is obvious flexibility at the ML-EH interface, which is in line with SAXS analysis demonstrating relatively more-, or less-, extended quasi-helical structures formed by discrete ASK3 homo-hexamers, or ASK1-ASK2 hetero-hexamers. Nonetheless, it remains unclear why the ASK SAM domain oligomers are self-limiting and discrete, even at concentrations exceeding $300 \mu \mathrm{M}$. While a closed hexameric-ring as a mechanism of self-limitation is a tempting proposition, strong evidence is still lacking. For instance, a near-closed ring is the best match for experimental SAXS data from ASK3 SAM, but such a closed hexamer is not seen within the 
crystal structure. As the data stand, we hypothesise that either a closed ring, or steric occlusion-through flexibility at the ML-EH interface or though the variable C-terminal tails of each SAM domain-cause the ASK SAM domains to form discrete, self-limiting oligomers. Another clear point for future investigation is how other structural elements found in fulllength ASK proteins, such as the kinase domain (that itself has been shown to dimerise) and the predicted $\mathrm{C}$-terminal coiled coil (directly $\mathrm{N}$-terminal to the SAM), might influence the oligomerisation behaviour of ASK1-3. Pertinent to this, the Kinase Suppressor of Ras (KSR) also contains a coiled-coil SAM domain arrangement. However, the CC-SAM of KSR is responsible for membrane association and/or scaffolding interactions with RAF MAP3Ks (46, $47)$, rather than higher-order oligomerisation. Nonetheless, our experiments in cells clearly show that the SAM domains play a major role in setting the stoichiometry of ASK signalosomes owing to ML-EH mutants exhibiting diminished stress-stimulated signalling. Previous studies of ASK1 incidentally bearing mutations (deletion or alanine mutations of Glycine1356/1357) of a similar surface also showed abrogated signalling in response to hydrogen peroxide, supporting a crucial role of the ML-EH surface in ASK signalling (27).

With growing knowledge of the domain structures of ASK kinases the obvious challenge is understanding how oligomerisation by the SAM at the C-terminus integrates with the raft of other interactions through their N-termini. Previously, we reported the crystal structure of the central regulatory region of ASK1-found N-terminal to the kinase domain-which links the $\mathrm{N}$-terminal thioredoxin-binding domain to the kinase domain (18). A pleckstrin-homology domain within this novel fold appears to promote substrate MAP2K phosphorylation, which could occur on an intra- or inter-molecular basis. Other partners also have distinct oligomeric states. For instance, Peroxiredoxin-1 has been demonstrated to transduce peroxide signals to ASK1 (48), and peroxiredoxin proteins frequently adopt ring-shaped decamers/dodecamer of five or six Prdx-1 dimers (49). Similarly, the phosphatase PGAM5 is known to target ASK1 (50), and structural studies have shown that PGAM5 forms dodecameric rings that are important for its activity on an ASK1 substrate peptide $(51,52)$. $\mathrm{N}$-terminal regions of ASK1 have been shown to interact with TNF receptor-associated factor type ubiquitin ligases (17), which form oligomers (53), and the F-box Cullin-ubiquitin ligase component Fbxo21 (31). Interestingly, the F-box protein FbxW11/ $\beta$ TrCP2 was also identified in our BiCAP analysis (Supp. Table 2), further reinforcing cross-regulation between ASK complexes and the ubiquitin proteasome system (54). Fbxo21 promotes Lys29-linked ubiquitination on ASK1 during viral infection (31), on lysine residues near the binding site for 14-3-3 proteins. 14-3-3 proteins are themselves dimeric regulators of ASK proteins that bind C-terminal to the kinase domain (19). Ultimately, many of the regulatory interactions of ASK 
kinases could be exacerbated, or compete, in the context of full-length proteins that are tethered through their $\mathrm{C}$-termini. Thus, there are multiple mechanisms by which ASK regulation-either autoinhibition or transactivation-stand to be enhanced by SAM domainbased oligomerisation.

Preferential hetero-oligomerisation between the ASK1 and ASK2 SAM domains is a relatively simple molecular mechanism to explain the greater efficacy in eliciting stress responses in various settings (4-8). With isolated SAM domains the heterocomplex appears to be more stable at equivalent concentrations, which if translated to full-length proteins would mean that higher-order active complexes form more readily and are more persistent. Several other additional questions remain; including whether other SAM domain containing proteins may also be able to participate in ASK SAM oligomers. There was some incorporation of ASK3 into ASK1 complexes isolated during BiCAP, however, no other obvious SAM domain-containing candidates were identified (Supp. Table 2). Addressing the propensity of the isolated ASK3 SAM domain to bind ASK1/2 SAM domains; GST pulldowns suggest that the monomeric ASK2 SAM domain could be bound by GST-ASK3 SAM domain, but the reciprocal interaction occurs less readily (Figure $3 A$ ). Such behaviour might be explained by the stability of the ASK3 complex over a large concentration range. In equivalent experiments ASK1-ASK3 interactions appear less likely. However, whether ASK3 actively participates in endogenous ASK $1 / 2$ complexes in cells is a relevant functional question.

Overall, this study uncovers a common protein-protein interaction domain that plays an important role in the function of ASK kinases-adding to the conserved repertoire of functional domains found in MAP kinases, and their scaffolding proteins, from yeast through to humans. These findings reinforce modularity of signalling cascades in eukaryotes, in a manner that maintains remarkable specificity despite structural similarity. ASK kinases appear to be particularly rich in autoregulatory interaction domains, in line with their role at the intersection of many cellular stresses. Understanding how the features work in concert, at the protein level and in cells, remains an ongoing challenge relevant to a multipurpose signalling hub. 


\section{Acknowledgements}

We thank members of the Mace Laboratory for useful discussions and assistance, particularly Pavel Filipčík for X-ray crystallography assistance. Various plasmids were kind gifts from Daniel Liebler, William Hahn, David Root, and Stephen Michnick (See Methods). This work was funded by the Marsden Fund of New Zealand; PDM was also supported by a Rutherford Discovery Fellowship administered by the Royal Society of New Zealand. Support is also acknowledged from the Victorian State Government Operational Infrastructure Support, NHMRC IRIISS grant (9000433), and an NHMRC fellowship (1105754; to J.M.M.). This research was undertaken in part using the small-angle X-ray scattering and the MX2 beamline at the Australian Synchrotron, part of ANSTO, and made use of the ACRF detector. We thank the New Zealand synchrotron group for facilitating access to the MX beamlines, and the Biomolecular Interaction Centre for AUC access. 


\section{Materials and Methods}

\section{DNA Constructs}

Tandem-tagged constructs for HEK293 expression and HNE induction (ASK1 (HA-Flag) and ASK2 (HA-V5) Addgene \# 69726, \#69727, respectively) were a kind gift from Daniel Liebler (28). For BiCAP experiments The pDONR223-MAP3K5 used (Addgene plasmid 23517) (55)) was a kind gift of Dr William Hahn and Dr David Root. An expression vector encoding full length Venus fluorescent protein was a kind gift from Dr Stephen Michnick (University of Montreal). The ASK1 SAM domain was amplified from the MegaMan Transcriptome library (Agilent). Constructs comprising ASK2 and ASK3 were amplified from Addgene plasmids (\#69727 and \#69728, respectively). Indicated fragments were cloned into a pET-LIC vector either containing an $\mathrm{N}$-terminal 6xHis or GST tag, and a 3C protease cleavage site. All mutants were generated using quikchange mutagenesis and verified by Sanger sequencing.

\section{Protein Expression and Purification}

All recombinant proteins were expressed in E. coli BL21(DE3) in LB media, induced with IPTG overnight at $18^{\circ} \mathrm{C}$, and lysed by sonication. ASK1 (1290-1374), ASK2 (1216-1288) and ASK3 (1241-1313) were initially purified from clarified $E$. coli lysate by $\mathrm{Ni}^{2+}$-affinity chromatography using HisSelect resin (Sigma), followed by size exclusion chromatography (Superdex 75 column; GE Healthcare), with a $3 \mathrm{C}$ cleavage step between. SEC was carried out using a buffer consisting of $10 \mathrm{mM}$ HEPES (pH 7.6), $150 \mathrm{mM} \mathrm{NaCl}$ and 2 mM DTT. Purified proteins were snap frozen in aliquots using liquid nitrogen.

\section{Analytical Ultracentrifugation}

Sedimentation velocity experiments using absorbance optics were conducted in a Beckman $\mathrm{XL}-\mathrm{I}$ analytical ultracentrifuge. Initial scans were performed at 3,000 rpm to determine the optimal wavelength for data collection. Experiments were conducted at $20^{\circ} \mathrm{C}$, the predetermined wavelength, continuous mode, 50,000 rpm in $20 \mathrm{mM}$ HEPES (pH 7.6), $150 \mathrm{mM}$ $\mathrm{NaCl} 0.2 \mathrm{mM}$ TCEP. Buffer density and viscosity and an estimate of the partial specific volume of proteins ( $v$-bar) was calculated using SEDNTERP. Data were fitted to a continuous sedimentation coefficient [c(s)] model using SEDFIT. Data were visualised by creating $\mathrm{c}(\mathrm{s})$ vs. s graphs using the GUSSI software. 


\section{Crystallisation and Structure Solution}

ASK3(1241-1313) was initially crystallised in 0.1 M Bis-Tris pH 6.5, $25 \%$ (w/v) PEG3350 at a 1:1 drop ratio. Optimisation was carried out using the Hampton Research stock options $\mathrm{pH}$ kit with diffracting crystals grown in $0.1 \mathrm{M}$ sodium citrate tribasic dihydrate $\mathrm{pH} \mathrm{5,} 25 \%(\mathrm{w} / \mathrm{v})$ PEG3350, and frozen with the addition of $20 \%$ (v/v) glycerol. X-ray diffraction data were collected at the Australian Synchrotron beamline MX2. Native and iodide soaked (0.5 M Nal) crystals were collected at 0.9357 and $1.456 \AA$ wavelengths, respectively. The structure was solved using single-wavelength anomalous dispersion, using a $1.8 \AA$ dataset. The AutoRickshaw webserver was used for structure solution by generating initial phases and an electron density map (56). An initial model was built by Buccaneer and improved using cycles of automated and manual refinement using the PDB_REDO web server (57), Phenix (58) and Coot (59). Structural figures were generated using PyMOL (Schrodinger).

\section{SEC-MALS}

SEC-MALS was conducted using a Wyatt Dawn 8+ detector (Wyatt Technology) coupled to a Superdex 75 10/300 column (GE Healthcare) and a refractive index detector. Samples were run in $10 \mathrm{mM}$ HEPES (pH 7.6), $150 \mathrm{mM} \mathrm{NaCl}$, and $0.3 \mathrm{mM}$ TCEP and loaded at 100 or 200 uM. All data were analyzed using ASTRA V software.

\section{Cell Lines and Cell Culture}

HEK-293FT cells were grown in DMEM (Life Technologies, 10566) supplemented with 10\% fetal bovine serum (Sigma-Aldrich, F8067), 2 mM L-glutamine (Life Technologies, 25030081), 100 units/mL Penicillin-Streptomycin (Life Technologies, 15140122), NonEssential Amino Acids (Hyclone, SH30238) and $1 \mathrm{mM}$ Sodium Pyruvate ((Hyclone, $\mathrm{SH} 3023901$ ). Cells were grown at $37^{\circ} \mathrm{C}$ in a humidified atmosphere with $5 \% \mathrm{CO}_{2}$.

\section{HNE Stimulation}

Cells were transiently co-transfected with Lipofectamine 3000 (Life Technologies, L3000015). A total of $3 \mu \mathrm{g}$ plasmid DNA was used; either $1.5 \mu \mathrm{g}$ of relevant ASK construct and/or pcDNA3. Cells were grown for twenty-four hours before 4-hydroxy-2-nonenal (HNE) treatment. One hour before treatment the medium was replaced with serum free- media. Cells were treated with either ethanol (vehicle control) or $50 \mu \mathrm{M} \mathrm{HNE}$ for $1 \mathrm{~h}$ at $37^{\circ} \mathrm{C}$. Cells were harvested into the treatment medium and centrifuged at $500 \times g$ for 5 min at $4{ }^{\circ} \mathrm{C}$. The cell pellets were washed twice with ice cold phosphate buffered saline (PBS) and the cell pellet resuspended in $100 \mu \mathrm{L}$ of $4 x$ SDS-PAGE Sample Buffer. Samples were frozen in liquid nitrogen and stored at $-80{ }^{\circ} \mathrm{C}$ until use. 


\section{Western Blotting}

For analysis by western blot, samples were separated by SDS/PAGE and transferred to 0.2 $\mu \mathrm{m}$ nitrocellulose (Life Technologies, IB23002). Membranes were blocked in 5\% BSA (w/v) in TBS-T. Membranes were incubated with primary antibodies overnight at $4^{\circ} \mathrm{C}$ in $5 \% \mathrm{BSA}$ $(w / v)$ in TBS-T. Antibodies used in this study were rabbit monoclonal p38 MAPK (1:2000, CST, \#8690), rabbit monoclonal Phospho-p38 MAPK (Thr180/Tyr182) (1:500, CST, \#4511), Phospho-ASK1 (Thr845) (1:1000, CST, \#3765), mouse monoclonal V5 tag (1:5000, Abcam, ab27671), rabbit monoclonal DYKDDDDK tag (Flag tag, 1:1000, CST, \#14793) and/or mouse monoclonal $\alpha$-tubulin (1:10,000, Millipore, 05-829). Following three washes with TBS$\mathrm{T}$, membranes were incubated with secondary antibodies diluted in TBS-T with $1 \%(\mathrm{w} / \mathrm{v})$ BSA for 1 hour at room temperature. Secondary antibodies used were goat anti-rabbit IRdye 680LT (LI-COR), goat anti-mouse IRdye 800LT (LI-COR) or goat anti-rabbit HRP-conjugated (1:10,000, Abcam, ab6721; used with Phospho-p38 MAPK). Membranes were washed a further three times with TBS-T. Membranes were then developed with the Odyssey Fc imaging system.

\section{Bimolecular complementation affinity purification}

Vectors expressing V1 or V2 tagged fusions of ASK1 were generated by recombination cloning into pDEST-V1 or pDEST-V2 destination vectors using Gateway LR Clonase enzyme mix (Life Technologies) according to manufacturer's instructions and verified by sequencing.

HEK293T cells were grown in $10 \mathrm{~cm}$ dishes and transfected with $2.5 \mu \mathrm{g}$ of each BiCAP construct using JETprime transfection reagent (Polyplus). After $16 \mathrm{~h}$, cells were harvested by washing twice with warm PBS and then scraping on ice with ice-cold lysis buffer $(50 \mathrm{mM}$ Tris $\mathrm{HCl} \mathrm{pH} \mathrm{7.4,} 150 \mathrm{mM} \mathrm{NaCl}, 1 \mathrm{mM}$ EDTA, 1\% (v/v) Triton X-100) supplemented with fresh EDTA-free protease inhibitor cocktail and $0.2 \mathrm{mM}$ sodium orthovanadate. Samples were cleared by centrifugation at $18000 \mathrm{~g}$ for $10 \mathrm{~min}$ at $4{ }^{\circ} \mathrm{C}$ to remove cellular debris, prior to proceeding with affinity purification using GFP-Trap_A agarose beads (ChromoTek GmbH), trypsin digestion and nanoLC-MS/MS as previously described in detail $(29,30)$.

\section{Small-Angle X-ray Scattering}

SAXS data was collected using the SAXS/WAXS beamline at the Australian Synchrotron with an inline gel-filtration chromatography setup (60-62). Protein samples (ASK1 SAM 50 $\mu \mathrm{L}$ at $9.2 \mathrm{mg} \cdot \mathrm{mL}^{-1}$; ASK2 SAM $90 \mu \mathrm{L}$ at $8.5 \mathrm{mg} \cdot \mathrm{mL}^{-1}$; ASK1+2 SAM $90 \mu \mathrm{L}$ at $5.2 \mathrm{mg} \cdot \mathrm{mL}^{-1}$; 
ASK3 SAM $50 \mu \mathrm{L}$ at $8.3 \mathrm{mg} \cdot \mathrm{mL}^{-1}$ ) were injected onto a Superdex 75 Increase $5 / 150$ column and eluted in $10 \mathrm{mM}$ HEPES pH 7.5, $150 \mathrm{mM} \mathrm{NaCl}, 5 \%$ glycerol and $0.2 \mathrm{mM}$ TCEP at a flow rate of $0.5 \mathrm{~mL}$. $\mathrm{min}^{-1}$. Protein was eluted from the column into a $1 \mathrm{~mm}$ diameter quartz capillary orthogonally aligned to the X-ray beam. The coflow system, providing sheath flow, was used to achieve stable laminar flow through the capillary reducing radiation damage (63). Data was collected at $285 \mathrm{~K}$ using an X-ray beam of $1.03 \AA$ in wavelength and $2 \mathrm{~s}$ exposure times. $\mathrm{X}$-ray scattering was measured by a Pilatus $1 \mathrm{M}$ or $2 \mathrm{M}$ detector (Dectris). Primary data reduction and buffer subtraction was performed onsite at the Australian Synchrotron using scatterBrain software developed in-house (Stephen Maudie, Australian Synchrotron). Data analysis was performed using Primus (64), GNOM (65), and Crysol (66) from the ATSAS package (67). 
Table 1: Crystallographic data

\begin{tabular}{|c|c|c|}
\hline \multicolumn{3}{|l|}{ Data Collection } \\
\hline ASK3 SAM domain & Native & lodide \\
\hline Beamline & AS-MX2 & AS-MX2 \\
\hline Wavelength $(\AA)$ & 0.9357 & 1.456 \\
\hline Resolution $(\AA)$ & $48.13-1.80(1.83-1.80)$ & $48.11-2.62(2.74-2.62)$ \\
\hline Space group & $P 212121$ & $P 212121$ \\
\hline $\begin{array}{c}\text { Unit cell parameters } \\
\text { a, b, } c(\AA) \\
\alpha, \beta, \gamma\left({ }^{\circ}\right)\end{array}$ & $\begin{array}{l}45.42,53.56,96.26 \\
90,90,90\end{array}$ & \\
\hline$R_{\text {merge }}$ (outer shell) & $0.053(0.985)$ & $0.114(0.474)$ \\
\hline$R_{\text {pim }}$ (outer shell) & $0.044(0.787)$ & $0.059(0.365)$ \\
\hline 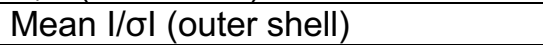 & $11.5(1.1)$ & $11.2(2.3)$ \\
\hline Completeness (outer shell) & $99.4(98.3)$ & $99.0(93.2)$ \\
\hline Multiplicity (outer shell) & $4.2(4.4)$ & $7.5(4.2)$ \\
\hline Total No. of reflections & 94216 & 56242 \\
\hline No. of unique reflections & 22425 & 7518 \\
\hline $\mathrm{CC}(1 / 2)$ (outer shell) & $0.998(0.455)$ & $0.997(0.749)$ \\
\hline Wilson $B$ factor $\left(\AA^{2}\right)$ & 35.05 & \\
\hline \multicolumn{3}{|l|}{ Refinement Statistics } \\
\hline$R_{\text {cryst }}$ & 0.2130 & \\
\hline$R_{\text {free }}$ & 0.2614 & \\
\hline rmsd for bonds $(\AA)$ & 0.013 & \\
\hline rmsd for angles (deg) & 1.30 & \\
\hline rmsd for chiral volume $\left(\AA^{3}\right)$ & 0.072 & \\
\hline No. of protein atoms & 1688 & \\
\hline No. of solvent atoms & 122 & \\
\hline Average $B$-factor overall $\left(\AA^{2}\right)$ & 39.36 & \\
\hline Average main chain $B$-factor $\left(\AA^{2}\right)$ & 38.93 & \\
\hline $\begin{array}{l}\text { Average side chain and solvent } B \text { - } \\
\text { factor }\left(\AA^{2}\right)\end{array}$ & 45.27 & \\
\hline \multicolumn{3}{|l|}{ Ramachandran plot statistics (\%) } \\
\hline Favoured regions & 99.5 & \\
\hline Allowed regions & 0 & \\
\hline Outliers & 0.5 & \\
\hline
\end{tabular}


Table 2: SAXS Data Parameters

\begin{tabular}{|c|c|c|c|c|}
\hline & ASK1 & ASK2 & ASK1+2 & ASK3 \\
\hline \multicolumn{5}{|c|}{ Data collection parameters } \\
\hline Instrument & \multicolumn{4}{|c|}{ Australian Synchrotron, SAXS/WAXS } \\
\hline Detector & \multicolumn{4}{|c|}{ Dectris-Pilatus $1 \mathrm{M}$ or $2 \mathrm{M}$} \\
\hline Wavelength, $\AA$ & \multicolumn{4}{|l|}{1.03} \\
\hline Exposure time, $s$ & \multicolumn{4}{|l|}{2} \\
\hline Temperature, $\mathrm{K}$ & \multicolumn{4}{|l|}{285} \\
\hline q range, $\AA^{-1}$ & $0.012-0.24$ & $0.012-0.23$ & $0.011-0.24$ & $0.012-0.23$ \\
\hline Protein concentration & $\begin{array}{l}50 \mathrm{uL} \text { of } 9.2 \\
\mathrm{mg} \cdot \mathrm{mL}^{-1}\end{array}$ & $\begin{array}{l}90 \mathrm{uL} \text { of } 8.5 \\
\mathrm{mg} \cdot \mathrm{mL}^{-1}\end{array}$ & $\begin{array}{l}90 \mathrm{uL} \text { of } 5.2 \\
\mathrm{mg} \cdot \mathrm{mL}^{-1}\end{array}$ & $\begin{array}{l}50 \mathrm{uL} \text { of } 8.3 \\
\mathrm{mg} \cdot \mathrm{mL}^{-1}\end{array}$ \\
\hline \multicolumn{5}{|l|}{ Structural parameters } \\
\hline$I(0), \mathrm{cm}^{-1}$, from $P(r)$ & $\begin{array}{l}0.0044 \pm \\
0.0005\end{array}$ & $0.0088 \pm 0.0008$ & $0.052 \pm 0.003$ & $0.019 \pm 0.001$ \\
\hline$R_{g} \AA$, from $P(r)$ & $14.2 \pm 0.00$ & $16.0 \pm 0.01$ & $29.2 \pm 0.05$ & $25.7 \pm 0.02$ \\
\hline$D_{\max }, \AA$ & 40 & 65 & 100 & 80 \\
\hline $\begin{array}{l}I(0), \mathrm{cm}^{-1}, \text { from } \\
\text { Guinier }\end{array}$ & $\begin{array}{l}0.0045 \pm \\
0.0002\end{array}$ & $0.0087 \pm 0.0002$ & $0.051 \pm 0.0009$ & $0.019 \pm 0.0006$ \\
\hline$R_{g} \AA$, from Guinier & $14.2 \pm 0.00$ & $16.0 \pm 0.01$ & $29.2 \pm 0.05$ & $25.2 \pm 0.02$ \\
\hline \multicolumn{5}{|l|}{ Software used } \\
\hline $\begin{array}{l}\text { Primary data } \\
\text { reduction }\end{array}$ & \multicolumn{4}{|l|}{ scatterBrain } \\
\hline Data processing & \multicolumn{4}{|c|}{ PRIMUS, GNOM } \\
\hline $\begin{array}{l}\text { Computation of } \\
\text { model intensities }\end{array}$ & \multicolumn{4}{|l|}{ CRYSOL } \\
\hline
\end{tabular}




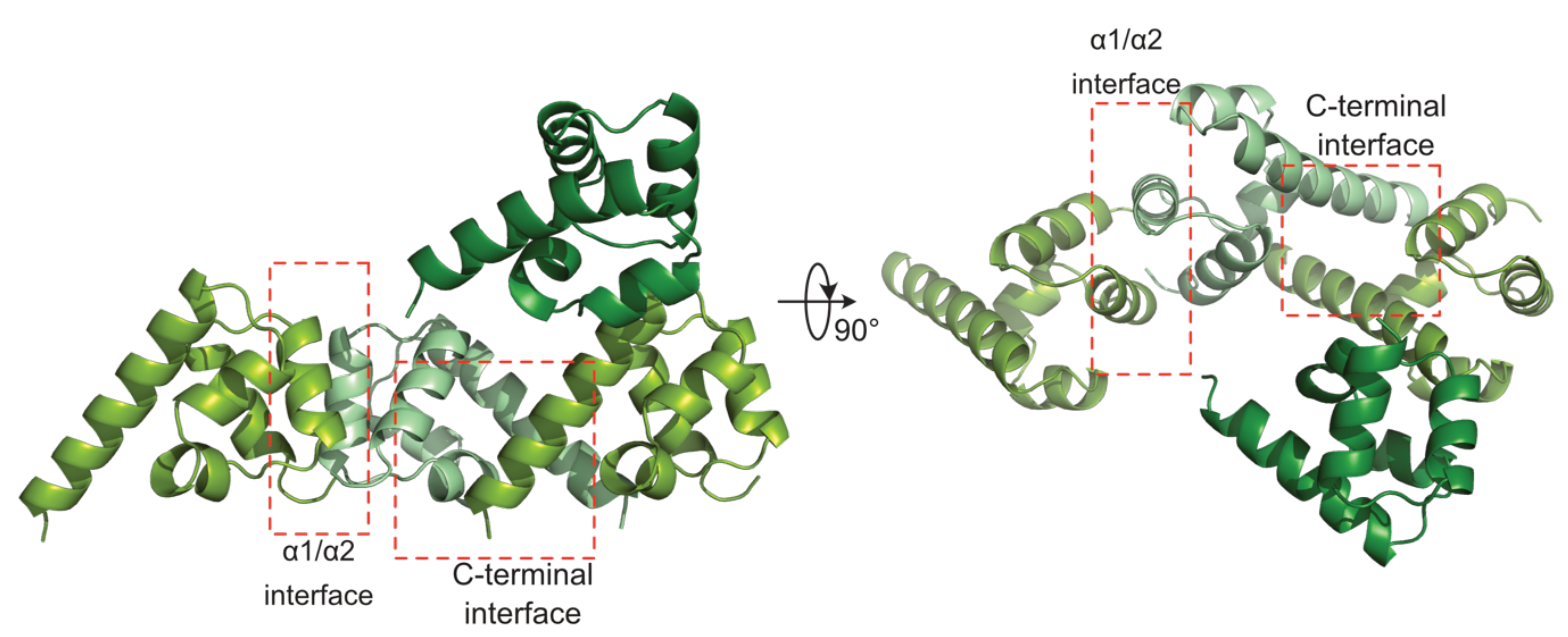

Supp. Fig. 1: ASK3 SAM crystal packing. Cartoon Illustration of the crystallographic asymmetric unit, and one SAM domain from a neighbouring asymmetric unit that interacts at the $\alpha 1 / \alpha 2$ interface. Interfaces referred to in the text are indicated

A

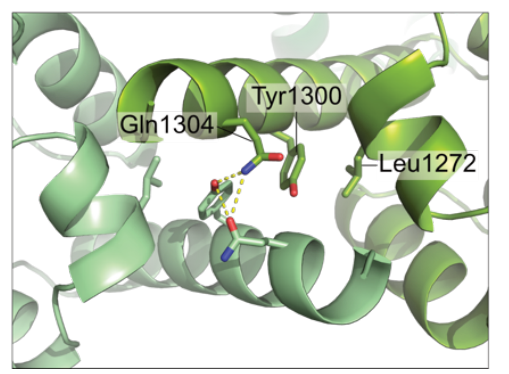

B

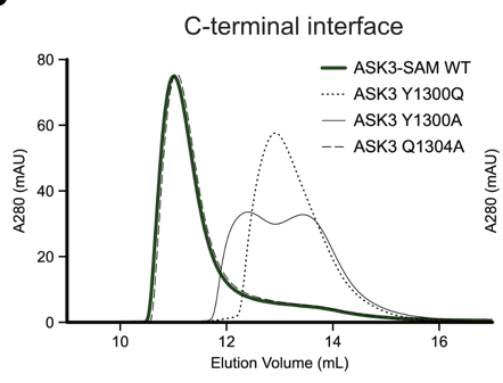

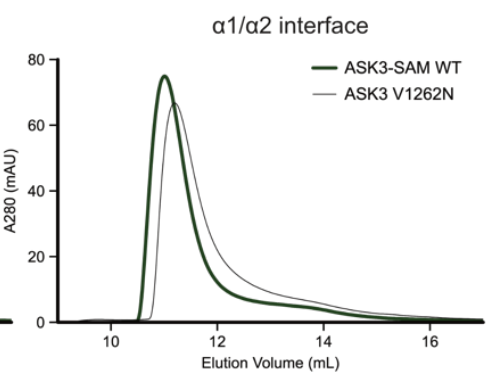

Supp. Fig. 2: Analysis of ASK3 SAM mutants (A) closeup view of residues at the C-terminal interface. (B) Size-exclusion chromatography of the WT ASK3 SAM and mutations at the C-terminal (left) and a1/a2 (right) interface. 

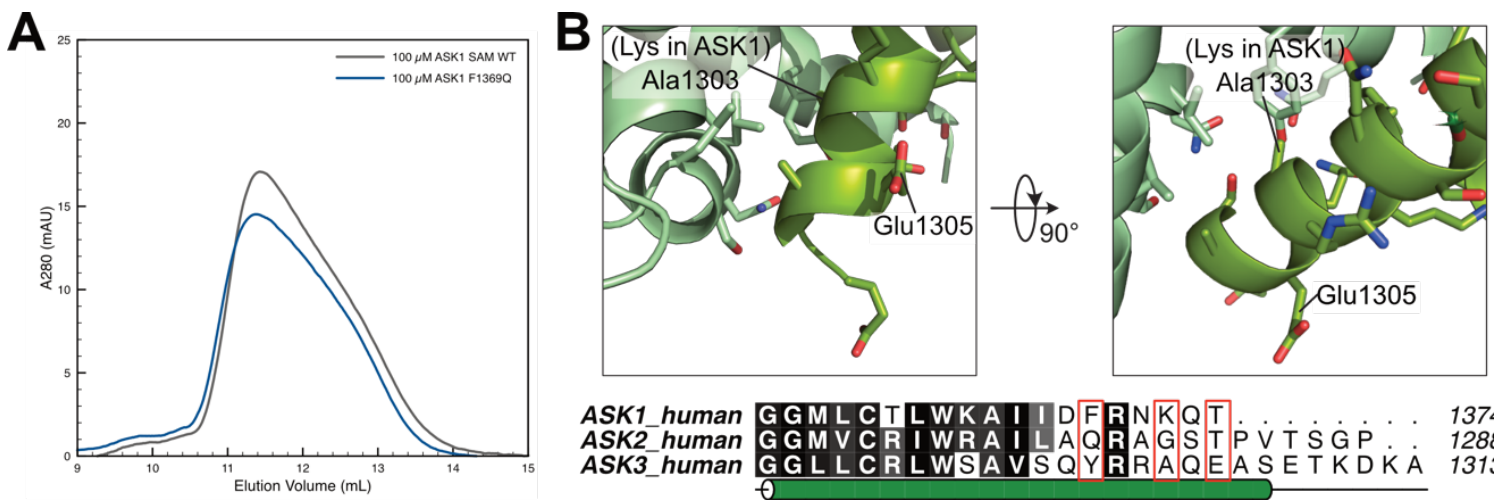

ASK1_human GGMLCTTWKA I I D FRN $\mathrm{K} Q \mathrm{Q} T$

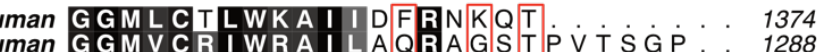
ASK3 ASK3_human GGLLCRLWSA VSQ Y R R A Q E A S E T KD K A 1313

C

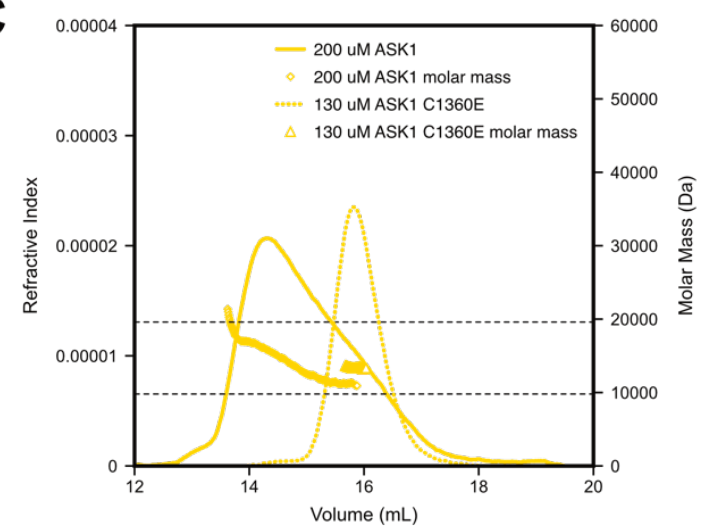

D

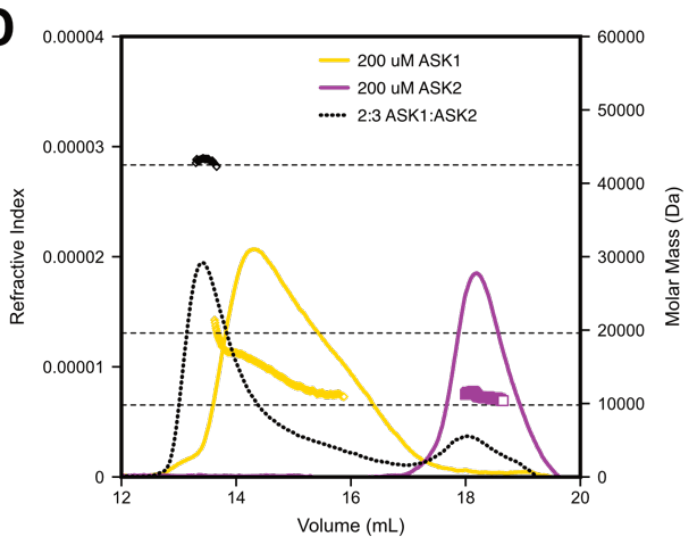

Supp. Fig. 3: Potential ASK1 oligomer interfaces. (A) Size-exclusion chromatography of WT ASK1 SAM and F1369Q mutation (equivalent to ASK3 Y1300Q). (B) Closeup view of the ASK3 C-terminal tail interaction, relative to sequence conservation in ASK1. Indicated on the alignment are ASK1/ASK3 residues F1369/Y1300, Lys1372/Ala1303 (which would could not be accomodated in a putative ASK1 complex), and Thr1374/Glu1305, to indicate the the position of the final residue of ASK1. (C) SEC-MALLS of WT and C1360E mutation of ASK1. (D) SEC MALS of WT ASK1, ASK2 and a mixture of the two SAM domains, each at a total concentration of $200 \mu M$.

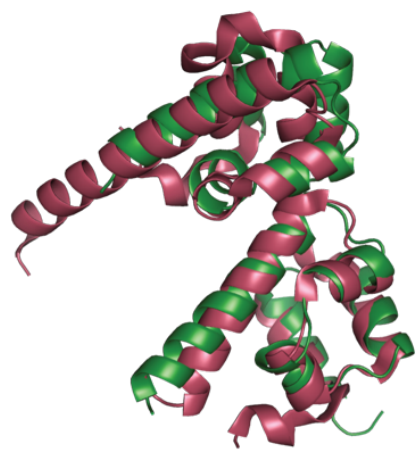

hCNK2-SAM/dHYP-SAM (PDB 3BS5)

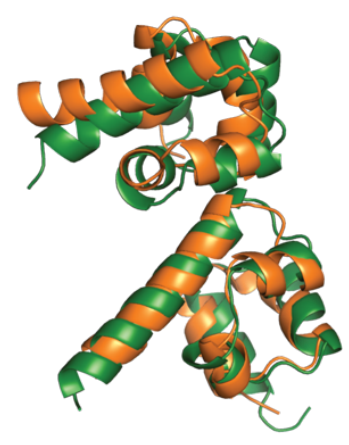

TNKS2-SAM (PDB 5JRT)

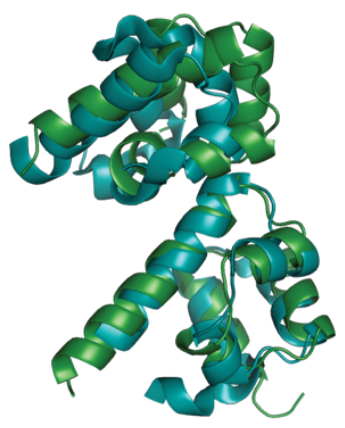

DAG kinase (PDB 3BQ7)

Supp. Fig. 4: Comparisons of the ML-EH pairwise interaction of ASK3 with indicated SAM ML-EH structures. 

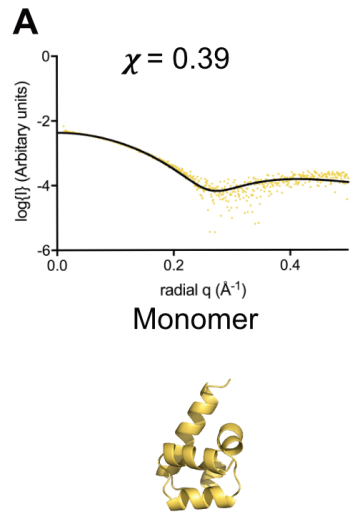

E

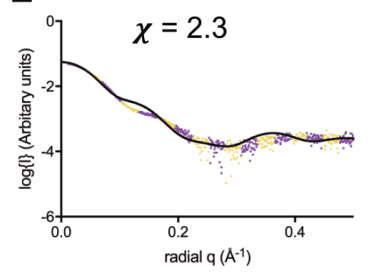

Hexamer ML-EH*
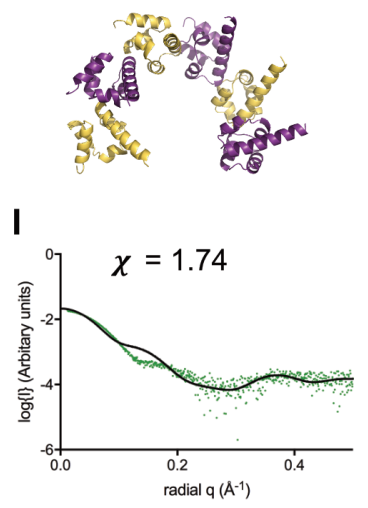

Hexamer ML-EH*

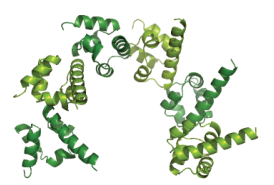

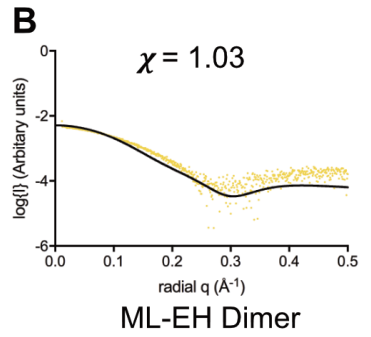

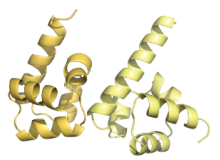

$\mathbf{F}$

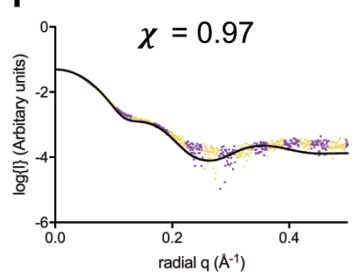

Hexamer ML-EH
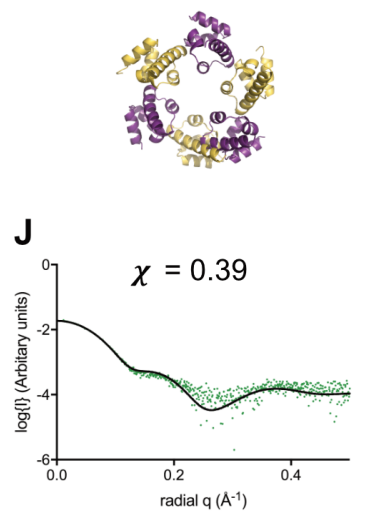

Hexamer ML-EH

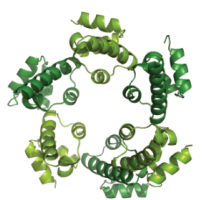

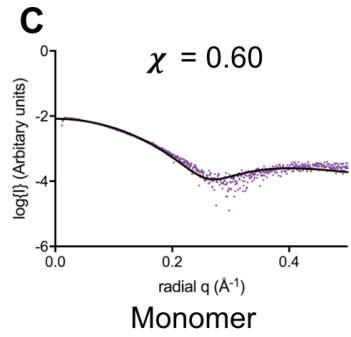
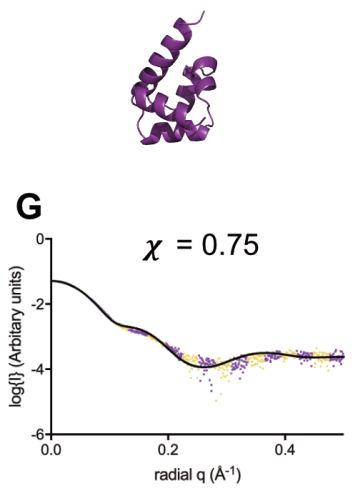

Hexamer Alternating $M L-E H: M L-E H$ *
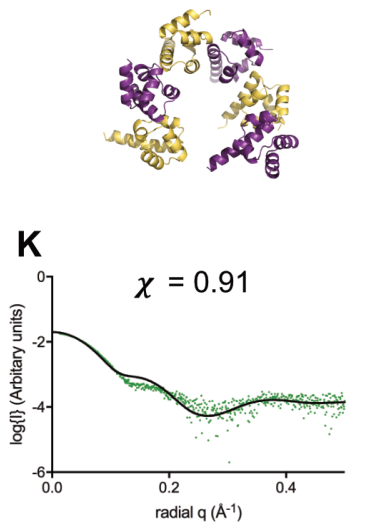

Hexamer Alternating ML-EH:ML-EH *

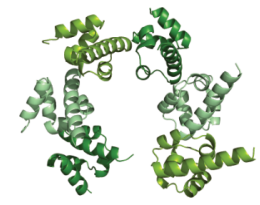

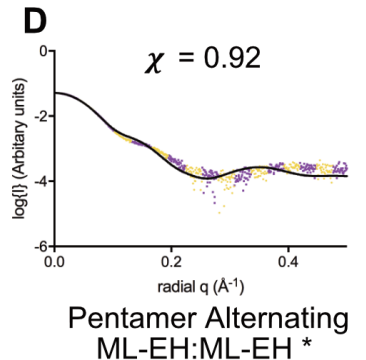

L-EH:ML-EH *
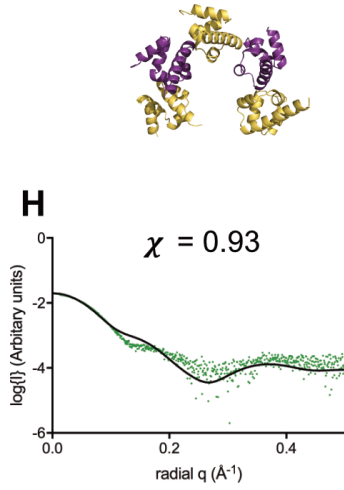

Pentamer Alternating $M L-E H: M L-E H$ *

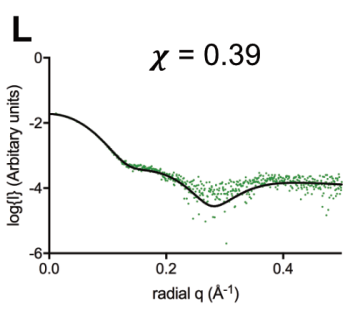

Hexamer 2XASU

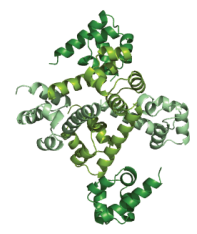

Supp. Fig. 5: Comparison of SAXS models to scattering data. CRYSOL fits of models to experimental SAXS scattering data, with corresponding model illustrated below for (A/B) ASK1 SAM; (C) ASK2 SAM; (D-G) ASK1+2 SAM; (H-L) ASK3 SAM. 
A

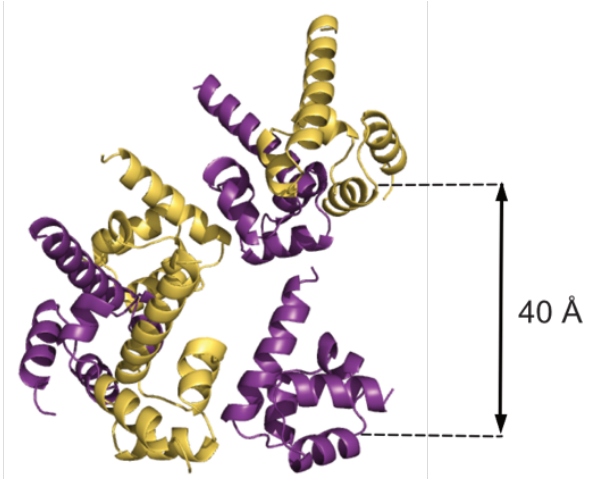

Alternating ML-EH:ML-EH*

C

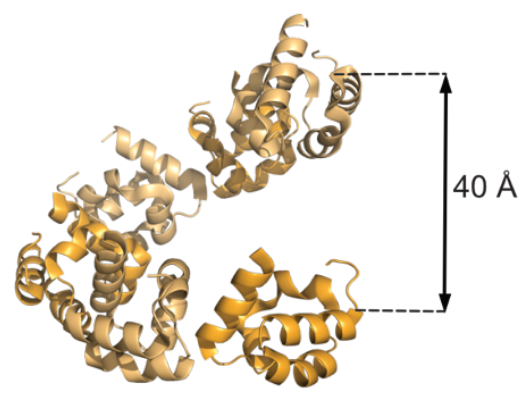

$2 \mathrm{~F} 3 \mathrm{~N}$

$\mathbf{E}$

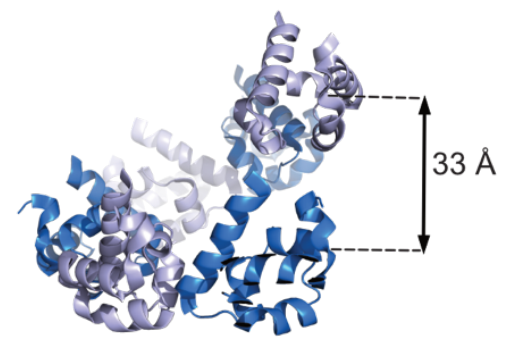

B

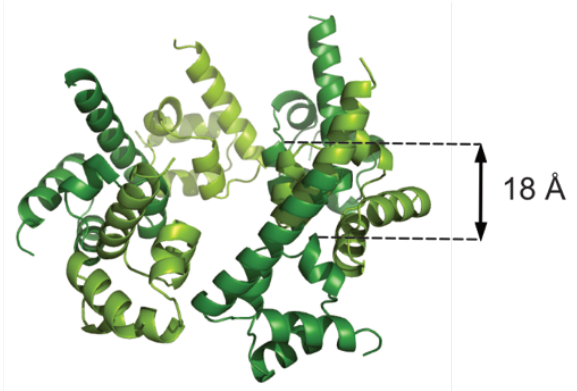

Repeating ML-EH

D

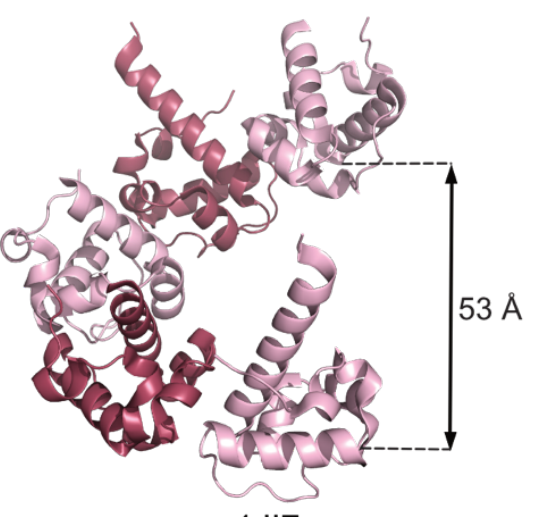

$\mathbf{F}$

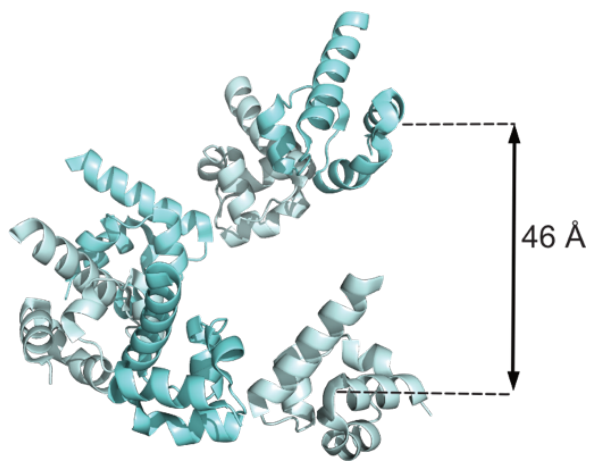

Supp. Fig. 6: Comparison of the pitch of helical filaments formed by SAM domain ML-EH interfaces. (A) Putative ASK1-ASK2 alternating ML-EH:ML-EH*. (B) Putative ASK3 repeating ML-EH. (C) SHANK3 from Rattus norvegicus (PDB ID: 2F3N). (D) Human ETS-related protein TEL1 (PDB ID: 1JI7). (E) Human Diacylgylcerol kinase 1 (PDB ID: 3BQ7). (F) Human Tankyrase 2 (PDB ID: 5JRT). 
Supp. Table 1: Summary of AUC data. ^ Frictional ratio determined by SEDFIT. * Weight averaged sedimentation coefficients obtained from the $c(s)$ distribution.

\begin{tabular}{|c|c|c|c|c|c|c|c|}
\hline & \multicolumn{2}{|c|}{ Concentration } & \multirow[t]{2}{*}{ rmsd } & \multirow[t]{2}{*}{$f / f_{0}^{\wedge}$} & \multirow[t]{2}{*}{ Z score } & \multirow{2}{*}{$\begin{array}{l}\text { Mass } \\
(\mathrm{kDa})\end{array}$} & \multirow[t]{2}{*}{$\mathrm{S}^{*}$} \\
\hline & $\mathrm{mg} / \mathrm{mL}$ & $\mu \mathrm{M}$ & & & & & \\
\hline \multirow{4}{*}{$\begin{array}{l}\text { ASK1 SAM } \\
\text { domain }\end{array}$} & 0.15 & 15 & 0.027 & 1.30 & 0.13 & $13.9,35.2$ & 2.05 \\
\hline & 0.3 & 31 & 0.028 & 1.50 & 1.19 & $14.5,40.7$ & 2.39 \\
\hline & 0.5 & 51 & 0.0093 & 1.27 & 0.02 & 33.7 & 2.77 \\
\hline & 1.5 & 153 & 0.010 & 1.42 & 1.34 & 41.9 & 2.85 \\
\hline \multirow{5}{*}{$\begin{array}{l}\text { ASK2 SAM } \\
\text { domain }\end{array}$} & 0.15 & 18 & 0.027 & 1.34 & 1.44 & 9.49 & 1.17 \\
\hline & 0.3 & 37 & 0.029 & 1.39 & 0.75 & 10.2 & 1.17 \\
\hline & 0.5 & 61 & 0.0097 & 1.46 & 0.03 & 11.7 & 1.26 \\
\hline & 1.5 & 183 & 0.010 & 1.35 & 3.96 & $10.6,25.4$ & 1.33 \\
\hline & 3 & 366 & 0.011 & 1.48 & 7.23 & $14.2,31.4$ & 1.64 \\
\hline \multirow{4}{*}{$\begin{array}{l}\text { ASK3 SAM } \\
\text { domain }\end{array}$} & 0.15 & 18 & 0.026 & 1.49 & 2.16 & $9.46,47.0$ & 2.76 \\
\hline & 0.3 & 36 & 0.027 & 1.42 & 0.42 & $9.36,44.4$ & 2.85 \\
\hline & 0.5 & 59 & 0.0097 & 1.35 & 1.44 & 41.3 & 2.92 \\
\hline & 1.5 & 177 & 0.010 & 1.40 & 1.02 & 44.3 & 2.95 \\
\hline ASK1+ASK2 & $1.5+1.5$ & 336 & 0.013 & 1.37 & 0.97 & $11.4,47.5$ & 2.81 \\
\hline
\end{tabular}


bioRxiv preprint doi: https://doi.org/10.1101/693663; this version posted July 5, 2019. The copyright holder for this preprint (which was not certified by peer review) is the author/funder. All rights reserved. No reuse allowed without permission.

Supp. Table 2: Summary of BiCAP mass spectrometry data

\begin{tabular}{|c|c|c|c|}
\hline Uniprot ID & Gene Name & $\begin{array}{l}\text { LOGV1_V2/Venu } \\
\text { s }\end{array}$ & $\begin{array}{l}\text { Student's } \\
\text { T-test p- } \\
\text { value } \\
\text { V1_V2 Vs } \\
\text { venus }\end{array}$ \\
\hline Q99683 & MAP3K5 & 9.111478043 & $2.01 \mathrm{E}-10$ \\
\hline P17066 & HSPA6 & 7.215911484 & 2.05E-08 \\
\hline Q9HDC5 & JPH1 & 7.15807724 & $4.98 \mathrm{E}-13$ \\
\hline Q9UKB1-2;Q9UKB1-3;Q9UKB1 & FBXW11 & 6.822875595 & $2.89 \mathrm{E}-08$ \\
\hline O95382-3;O95382;H0Y894;O95382-2 & MAP3K6 & 6.79411544 & $2.79 \mathrm{E}-09$ \\
\hline Q9P035;H3BS72;H3BPZ1 & HACD3 & 6.097149277 & $9.72 \mathrm{E}-07$ \\
\hline O95816;095816-2 & BAG2 & 5.899987411 & $2.42 \mathrm{E}-10$ \\
\hline Q9NWK9-2;Q9NWK9 & ZNHIT6 & 5.653740692 & $1.92 \mathrm{E}-07$ \\
\hline P28072 & PSMB6 & 5.287608337 & $3.46 \mathrm{E}-06$ \\
\hline $\begin{array}{l}\text { P32121-5;P32121-2;P32121;P32121-3;P32121- } \\
\text { 4;K7ENA6;Q68DZ5 }\end{array}$ & $\begin{array}{l}\text { ARRB2;DKFZp686L036 } \\
5\end{array}$ & 5.165010452 & 1.04E-09 \\
\hline $\mathrm{P} 11441 ; \mathrm{Q} 5 \mathrm{HY} 81$ & UBL4A & 5.016114807 & $2.70 \mathrm{E}-08$ \\
\hline $000232 ; 000232-2$ & PSMD12 & 4.964142609 & $1.02 \mathrm{E}-05$ \\
\hline $\begin{array}{l}\text { F8W126;Q96EZ8-3;Q96EZ8;Q96EZ8- } \\
\text { 2;F8W019;F8VVA6;F8VP44;Q96EZ8-4 }\end{array}$ & MCRS1 & 4.779930878 & $6.41 \mathrm{E}-08$ \\
\hline P68133;P68032;P63267;P62736;A6NL76 & ACTA1; & 4.626826477 & $1.31 \mathrm{E}-05$ \\
\hline P05386 & RPLP1 & 4.558090973 & $3.88 \mathrm{E}-05$ \\
\hline Q8WUY1 & THEM6 & 4.488477325 & $3.12 \mathrm{E}-06$ \\
\hline P05387 & RPLP2 & 4.487678146 & $6.36 \mathrm{E}-05$ \\
\hline P51665;H3BNT7;H3BTM8 & PSMD7 & 4.205415726 & $2.18 \mathrm{E}-07$ \\
\hline G3V5Z7;P60900;G3V295;G3V3I1;P60900-2;G3V3U4 & PSMA6 & 4.162992859 & $8.06 \mathrm{E}-06$ \\
\hline O95372;Q5QPQ0;Q5QPQ1;Q5QPQ3;Q5QPQ2 & LYPLA2 & 4.161015701 & $5.27 \mathrm{E}-05$ \\
\hline Q9NXW2;J3KPS0;Q9NXW2-2;V9GYN7 & DNAJB12 & 4.103730011 & $3.58 \mathrm{E}-06$ \\
\hline Q9UNY4;Q9UNY4-2 & TTF2 & 4.068842316 & $6.67 \mathrm{E}-10$ \\
\hline Q9BVV7;J3QRI1 & TIMM21 & 4.059252548 & $9.06 \mathrm{E}-07$ \\
\hline Q9P0L0 & VAPA & 3.949964523 & $2.53 \mathrm{E}-07$ \\
\hline A0A0G2JIW1;P0DMV9;P0DMV8;P0DMV8-2;V9GZ37 & HSPA1B;HSPA1A & 3.917794037 & $3.98 \mathrm{E}-08$ \\
\hline P28066 & PSMA5 & 3.719274521 & $6.82 \mathrm{E}-06$ \\
\hline Q96LL9 & DNAJC30 & 3.679924011 & $8.86 \mathrm{E}-09$ \\
\hline P07900;P07900-2 & HSP90AA1 & 3.6664505 & 3.35E-07 \\
\hline P62244;I3L3P7 & RPS15A & 3.653486252 & $5.94 \mathrm{E}-06$ \\
\hline Q99460-2;Q99460;A0A087WW66 & PSMD1 & 3.642589569 & $1.50 \mathrm{E}-07$ \\
\hline Q99442;F8WF48;F8WCJ7 & SEC62 & 3.613027191 & $2.44 \mathrm{E}-05$ \\
\hline P12235;V9GYG0 & SLC25A4 & 3.603698476 & 0.0134675 \\
\hline $\begin{array}{l}\text { E9PKG1;H7C2I1;Q99873-3;Q99873-2;Q99873- } \\
\text { 4;Q99873;A0A087X1W2;E9PNR9;E9PQ98;E9PIX6;H0YD } \\
\text { E4 }\end{array}$ & PRMT1 & 3.553664017 & $1.30 \mathrm{E}-05$ \\
\hline Q96EY1 & DNAJA3 & 3.548937225 & $8.00 \mathrm{E}-06$ \\
\hline P11142;E9PKE3;E9PNE6;P11142-2;E9PN89 & HSPA8 & 3.538095474 & $2.49 \mathrm{E}-08$ \\
\hline C9J9K3;A0A0C4DG17;P08865;F8WD59 & RPSA & 3.464690018 & $1.36 \mathrm{E}-06$ \\
\hline P61088;F8VSD4;F8VV71;Q5JXB2;F8VZ29 & UBE2N;UBE2NL & 3.426558304 & $\begin{array}{l}0.00135762 \\
1\end{array}$ \\
\hline P25788-2;P25788;G3V4X5 & PSMA3 & 3.420283508 & $1.19 \mathrm{E}-05$ \\
\hline B7Z3H4;Q9Y297-2;Q9Y297 & BTRC & 3.411013412 & $1.16 \mathrm{E}-06$ \\
\hline Q6ZN16;Q6ZN16-2;Q6ZN16-3 & MAP3K15 & 3.408455658 & $\begin{array}{l}0.00013928 \\
3\end{array}$ \\
\hline Q96TC7;HOYNE5;HOYLG5 & RMDN3 & 3.396035767 & $6.95 \mathrm{E}-07$ \\
\hline J9JIE6;Q9UM00-2;Q9UM00;J3KS45;J3KTQ7 & TMCO1 & 3.384986877 & $2.12 \mathrm{E}-07$ \\
\hline A0A0C4DGS1;P39656-3;P39656;P39656-2;U3KQ84 & DDOST & 3.381909943 & $3.09 \mathrm{E}-05$ \\
\hline Q8TF72 & SHROOM3 & 3.368126551 & $\begin{array}{l}0.00128920 \\
6\end{array}$ \\
\hline Q15773;F5H0Y3 & MLF2 & 3.356116104 & $3.36 \mathrm{E}-06$ \\
\hline Q14004-2;Q14004 & CDK13 & 3.35424118 & 3.32E-06 \\
\hline Q9Y2A7;Q9Y2A7-2 & NCKAP1 & 3.353968048 & $5.50 \mathrm{E}-06$ \\
\hline Q2M1P5 & KIF7 & 3.347851181 & $3.21 \mathrm{E}-06$ \\
\hline A0A0C4DGX4;Q13616 & CUL1 & 3.343305969 & $2.92 \mathrm{E}-07$ \\
\hline 095292 & VAPB & 3.310840225 & $8.86 \mathrm{E}-10$ \\
\hline P31689;P31689-2 & DNAJA1 & 3.308489227 & 4.94E-06 \\
\hline Q13131;Q13131-2 & PRKAA1 & 3.305492783 & $5.29 \mathrm{E}-08$ \\
\hline B4DZG7;P40616-2;P40616;F8VYN9 & ARL1 & 3.301347733 & 0.00027877 \\
\hline Q13200;Q13200-3;Q13200-2 & PSMD2 & 3.276361847 & $6.74 \mathrm{E}-05$ \\
\hline
\end{tabular}


bioRxiv preprint doi: https://doi.org/10.1101/693663; this version posted July 5, 2019. The copyright holder for this preprint (which was not certified by peer review) is the author/funder. All rights reserved. No reuse allowed without permission.

\begin{tabular}{|l|l|l|l|}
\hline Q9ULR0;Q9ULR0-2;Q9ULR0-1;D6RC18;A8MVI5 & ISY1 & 3.247544861 & $\begin{array}{l}0.00064161 \\
2\end{array}$ \\
\hline Q9ULC4;Q9ULC4-3;Q9ULC4-2 & MCTS1 & 3.243811798 & $6.72 \mathrm{E}-05$ \\
\hline Q9Y224;G3V4C6 & C14orf166 & 3.225773621 & $6.42 \mathrm{E}-05$ \\
\hline P49721 & PSMB2 & 3.193957901 & $3.80 \mathrm{E}-08$ \\
\hline Q9UBV8 & PEF1 & 3.18748436 & $\begin{array}{l}0.00043639 \\
2\end{array}$ \\
\hline P51970 & NDUFA8 & 3.176853943 & $1.85 \mathrm{E}-07$ \\
\hline Q5QPK2;O60762;H0Y368;Q5QPJ9 & DPM1 & 3.160103607 & $2.87 \mathrm{E}-09$ \\
\hline Q969G6 & RFK & 3.156514359 & $1.25 \mathrm{E}-06$ \\
\hline O00487 & PSMD14 & 3.134038162 & 0.00011324 \\
& & & 5 \\
\hline Q13724;Q13724-2;C9J8D4 & MOGS & 3.112656403 & $1.41 \mathrm{E}-05$ \\
\hline O15144 & ARPC2 & 3.102633286 & $8.96 \mathrm{E}-07$ \\
\hline P55795 & HNRNPH2 & 3.083833694 & 0.00044254 \\
& & 3.07906456 & 0.00065974 \\
\hline Q9NS86 & LANCL2 & 6 \\
\hline P23396;P23396- & & & $6.08 \mathrm{E}-10$ \\
\hline 2;E9PL09;E9PPU1;F2Z2S8;H0YCJ7;H0YEU2 & RPS3 & 3.072836304 & $6.78 \mathrm{E}-08$ \\
\hline Q36542 & & 3.055216217 & $1.11 \mathrm{E}-05$ \\
\hline Q96AG4 & ATP5C1 & 3.033669662 & $3.28 \mathrm{E}-07$ \\
\hline Q9UNM6;Q9UNM6-2;A0A087WUL9;J3KNQ3 & LRRC59 & 3.02738266 & 0.00080627 \\
\hline
\end{tabular}


Supp. Table 3: Summary of experimental SAXS data fit to possible oligomeric models

\begin{tabular}{|c|c|c|c|c|c|c|}
\hline & \multicolumn{2}{|c|}{ Experimental Data } & \multicolumn{4}{|c|}{ Models } \\
\hline & $R_{g}$ & $D_{\max }(\AA)$ & Model & $\begin{array}{c}\text { Theoretical } \\
\qquad R_{g}\end{array}$ & $\begin{array}{l}\text { Diameter } \\
(\AA)\end{array}$ & Fit $\chi$ \\
\hline \multirow[t]{4}{*}{ ASK1 SAM } & \multirow[t]{4}{*}{14.3} & \multirow[t]{4}{*}{40} & Monomer & 13.6 & 30 & 0.39 \\
\hline & & & $\begin{array}{l}\text { ML-EH } \\
\text { Dimer }\end{array}$ & 16.5 & 40 & 1.03 \\
\hline & & & $\alpha 3-4$ Dimer & 18.5 & & 1.00 \\
\hline & & & $\alpha 5$ Dimer & 17.2 & & 1.00 \\
\hline ASK2 SAM & 16.0 & 65 & Monomer & 13.9 & 30 & 0.60 \\
\hline \multirow[t]{4}{*}{$\begin{array}{l}\text { ASK1+2 } \\
\text { SAM }\end{array}$} & \multirow[t]{4}{*}{29.2} & \multirow[t]{4}{*}{100} & $\begin{array}{l}\text { Alternating } \\
\text { Pentamer }\end{array}$ & 29.0 & 78 & 0.91 \\
\hline & & & $\begin{array}{l}\text { Alternating } \\
\text { Hexamer }\end{array}$ & 28.6 & 77 & 0.67 \\
\hline & & & $\begin{array}{c}\text { ML-EH } \\
\text { Hexamer }\end{array}$ & 27.3 & 68 & 0.97 \\
\hline & & & $\begin{array}{l}\text { ML-EH }{ }^{*} \\
\text { Hexamer }\end{array}$ & 28.7 & 75 & 0.74 \\
\hline \multirow[t]{4}{*}{ ASK3 SAM } & \multirow[t]{4}{*}{25.8} & \multirow[t]{4}{*}{80} & $\begin{array}{l}\text { Alternating } \\
\text { Pentamer }\end{array}$ & 27.6 & 78 & 0.93 \\
\hline & & & $\begin{array}{l}\text { Alternating } \\
\text { Hexamer }\end{array}$ & 27.4 & 77 & 0.91 \\
\hline & & & $\begin{array}{l}\text { ML-EH } \\
\text { Hexamer }\end{array}$ & 25.4 & 68 & 0.39 \\
\hline & & & $\begin{array}{l}\text { ML-EH* } \\
\text { Hexamer }\end{array}$ & 27.5 & 75 & 0.96 \\
\hline
\end{tabular}




\section{References}

1. Ichijo, H., Nishida, E., Irie, K., ten Dijke, P., Saitoh, M., Moriguchi, T., Takagi, M., Matsumoto, K., Miyazono, K., and Gotoh, Y. (1997) Induction of apoptosis by ASK1, a mammalian MAPKKK that activates SAPK/JNK and p38 signaling pathways, Science, American Association for the Advancement of Science 275, 90-94.

2. Hattori, K., Naguro, I., Runchel, C., and Ichijo, H. (2009) The roles of ASK family proteins in stress responses and diseases, Cell Commun. Signal. 7, 9.

3. Kawarazaki, Y., Ichijo, H., and Naguro, I. (2014) Apoptosis signal-regulating kinase 1 as a therapeutic target, Expert Opin. Ther. Targets 18, 651-664.

4. Takeda, K., Shimozono, R., Noguchi, T., Umeda, T., Morimoto, Y., Naguro, I., Tobiume, K., Saitoh, M., Matsuzawa, A., and Ichijo, H. (2007) Apoptosis signalregulating kinase (ASK) 2 functions as a mitogen-activated protein kinase kinase kinase in a heteromeric complex with ASK1, J. Biol. Chem. 282, 7522-7531.

5. Okazaki, T., Higuchi, M., Takeda, K., Iwatsuki-Horimoto, K., Kiso, M., Miyagishi, M., Yanai, H., Kato, A., Yoneyama, M., Fujita, T., Taniguchi, T., Kawaoka, Y., Ichijo, H., and Gotoh, Y. (2015) The ASK family kinases differentially mediate induction of type I interferon and apoptosis during the antiviral response, Sci. Signal., AAAS 8, ra78ra78.

6. Iriyama, T., Takeda, K., Nakamura, H., Morimoto, Y., Kuroiwa, T., Mizukami, J., Umeda, T., Noguchi, T., Naguro, I., Nishitoh, H., Saegusa, K., Tobiume, K., Homma, T., Shimada, Y., Tsuda, H., Aiko, S., Imoto, I., Inazawa, J., Chida, K., Kamei, Y., Kozuma, S., Taketani, Y., Matsuzawa, A., and Ichijo, H. (2009) ASK1 and ASK2 differentially regulate the counteracting roles of apoptosis and inflammation in tumorigenesis, EMBO J., EMBO Press 28, 843-853.

7. Place, D. E., Samir, P., Karki, R., Briard, B., Vogel, P., and Kanneganti, T.-D. (2018) ASK Family Kinases Are Required for Optimal NLRP3 Inflammasome Priming, Am. J. Pathol. 188, 1021-1030.

8. Tartey, S., Gurung, P., Dasari, T. K., Burton, A., and Kanneganti, T.-D. (2018) ASK1/2 signaling promotes inflammation in a mouse model of neutrophilic dermatosis, J. Clin. Invest. 128, 2042-2047.

9. Naguro, I., Umeda, T., Kobayashi, Y., Maruyama, J., Hattori, K., Shimizu, Y., Kataoka, K., Kim-Mitsuyama, S., Uchida, S., Vandewalle, A., Noguchi, T., Nishitoh, H., Matsuzawa, A., Takeda, K., and Ichijo, H. (2012) ASK3 responds to osmotic stress and regulates blood pressure by suppressing WNK1-SPAK/OSR1 signaling in the kidney, Nat. Commun., Nature Publishing Group 3, 1285.

10. Loomba, R., Lawitz, E., Mantry, P. S., Jayakumar, S., Caldwell, S. H., Arnold, H., Diehl, A. M., Djedjos, C. S., Han, L., Myers, R. P., Subramanian, G. M., McHutchison, J. G., Goodman, Z. D., Afdhal, N. H., Charlton, M. R., and GS-US-384-1497 Investigators. (2017) The ASK1 inhibitor selonsertib in patients with nonalcoholic steatohepatitis: A randomized, phase 2 trial, Hepatology 67, 549-559.

11. Stark, M. S., Woods, S. L., Gartside, M. G., Bonazzi, V. F., Dutton-Regester, K., Aoude, L. G., Chow, D., Sereduk, C., Niemi, N. M., Tang, N., Ellis, J. J., Reid, J., Zismann, V., Tyagi, S., Muzny, D., Newsham, I., Wu, Y., Palmer, J. M., Pollak, T., Youngkin, D., Brooks, B. R., Lanagan, C., Schmidt, C. W., Kobe, B., MacKeigan, J. P., Yin, H., Brown, K. M., Gibbs, R., Trent, J., and Hayward, N. K. (2011) Frequent somatic mutations in MAP3K5 and MAP3K9 in metastatic melanoma identified by exome sequencing, Nat. Genet. 44, 165-169.

12. Hayakawa, Y., Hirata, Y., Nakagawa, H., Sakamoto, K., Hikiba, Y., Kinoshita, H., Nakata, W., Takahashi, R., Tateishi, K., Tada, M., Akanuma, M., Yoshida, H., Takeda, K., Ichijo, H., Omata, M., Maeda, S., and Koike, K. (2011) Apoptosis signal-regulating kinase 1 and cyclin D1 compose a positive feedback loop contributing to tumor growth in gastric cancer, Proc. Natl. Acad. Sci. U. S. A., National Acad Sciences 108, 780785.

13. Hayakawa, Y., Hirata, Y., Sakitani, K., Nakagawa, H., Nakata, W., Kinoshita, H., Takahashi, R., Takeda, K., Ichijo, H., Maeda, S., and Koike, K. (2012) Apoptosis signal-regulating kinase- 1 inhibitor as a potent therapeutic drug for the treatment of gastric cancer, Cancer Sci. 103, 2181-2185. 
14. Zhang, P., Wang, P.-X., Zhao, L.-P., Zhang, X., Ji, Y.-X., Zhang, X.-J., Fang, C., Lu, Y.-X., Yang, X., Gao, M.-M., Zhang, Y., Tian, S., Zhu, X.-Y., Gong, J., Ma, X.-L., Li, F., Wang, Z., Huang, Z., She, Z.-G., and Li, H. (2017) The deubiquitinating enzyme TNFAIP3 mediates inactivation of hepatic ASK1 and ameliorates nonalcoholic steatohepatitis, Nat. Med., Nature Publishing Group 62, S47.

15. Liles, J. T., Corkey, B. K., Notte, G. T., Budas, G. R., Lansdon, E. B., HinojosaKirschenbaum, F., Badal, S. S., Lee, M., Schultz, B. E., Wise, S., Pendem, S., Graupe, M., Castonguay, L., Koch, K. A., Wong, M. H., Papalia, G. A., French, D. M., Sullivan, T., Huntzicker, E. G., Ma, F. Y., Nikolic-Paterson, D. J., Altuhaifi, T., Yang, H., Fogo, A. B., and Breckenridge, D. G. (2018) ASK1 contributes to fibrosis and dysfunction in models of kidney disease, J. Clin. Invest.

16. Bunkoczi, G., Salah, E., Filippakopoulos, P., Fedorov, O., Müller, S., Sobott, F., Parker, S. A., Zhang, H., Min, W., Turk, B. E., and Knapp, S. (2007) Structural and functional characterization of the human protein kinase ASK1, Structure, Elsevier Ltd $15,1215-1226$.

17. Fujino, G., Noguchi, T., Matsuzawa, A., Yamauchi, S., Saitoh, M., Takeda, K., and Ichijo, $\mathrm{H}$. (2007) Thioredoxin and TRAF family proteins regulate reactive oxygen species-dependent activation of ASK1 through reciprocal modulation of the N-terminal homophilic interaction of ASK1, Mol. Cell. Biol., American Society for Microbiology 27, 8152-8163.

18. Weijman, J. F., Kumar, A., Jamieson, S. A., King, C. M., Caradoc-Davies, T. T., Ledgerwood, E. C., Murphy, J. M., and Mace, P. D. (2017) Structural basis of autoregulatory scaffolding by apoptosis signal-regulating kinase 1, Proc. Natl. Acad. Sci. U. S. A., National Acad Sciences 114, E2096-E2105.

19. Petrvalska, O., Kosek, D., Kukacka, Z., Tosner, Z., Man, P., Vecer, J., Herman, P., Obsilova, V., and Obsil, T. (2016) Structural Insight into the 14-3-3 Protein-dependent Inhibition of Protein Kinase ASK1 (Apoptosis Signal-regulating kinase 1), J. Biol. Chem., ASBMB 291, 20753-20765.

20. Miyakawa, K., Matsunaga, S., Kanou, K., Matsuzawa, A., Morishita, R., Kudoh, A., Shindo, K., Yokoyama, M., Sato, H., Kimura, H., Tamura, T., Yamamoto, N., Ichijo, H., Takaori-Kondo, A., and Ryo, A. (2015) ASK1 restores the antiviral activity of APOBEC3G by disrupting HIV-1 Vif-mediated counteraction, Nat. Commun., Nature Publishing Group 6, 6945.

21. Jaroszewski, L., Rychlewski, L., Li, Z., Li, W., and Godzik, A. (2005) FFAS03: a server for profile--profile sequence alignments, Nucleic Acids Res. 33, W284-8.

22. Sathyamurthy, A., Freund, S. M. V., Johnson, C. M., Allen, M. D., and Bycroft, M. (2011) Structural basis of p63a SAM domain mutants involved in AEC syndrome, FEBS J. 278, 2680-2688.

23. Mariotti, L., Templeton, C. M., Ranes, M., Paracuellos, P., Cronin, N., Beuron, F., Morris, E., and Guettler, S. (2016) Tankyrase Requires SAM Domain-Dependent Polymerization to Support Wnt- $\beta$-Catenin Signaling, Mol. Cell, Elsevier Inc. 63, 498513.

24. Riccio, A. A., McCauley, M., Langelier, M.-F., and Pascal, J. M. (2016) Tankyrase Sterile a Motif Domain Polymerization Is Required for Its Role in Wnt Signaling, Structure 24, 1573-1581.

25. Kwan, J. J., Warner, N., Pawson, T., and Donaldson, L. W. (2004) The solution structure of the S.cerevisiae Ste11 MAPKKK SAM domain and its partnership with Ste50, J. Mol. Biol. 342, 681-693.

26. Schneider, J. R., Lodolce, J. P., and Boone, D. L. (2013) An Ubiquitin-like Motif in ASK1 Mediates its Association with and Inhibition of the Proteasome, J. Biochem. Pharmacol. Res. 1, 161-167.

27. Nagai, H., Noguchi, T., Homma, K., Katagiri, K., Takeda, K., Matsuzawa, A., and Ichijo, H. (2009) Ubiquitin-like sequence in ASK1 plays critical roles in the recognition and stabilization by USP9X and oxidative stress-induced cell death, Mol. Cell, Elsevier Inc. 36, 805-818.

28. Federspiel, J. D., Codreanu, S. G., Palubinsky, A. M., Winland, A. J., Betanzos, C. M., McLaughlin, B., and Liebler, D. C. (2016) Assembly Dynamics and Stoichiometry of the Apoptosis Signal-regulating Kinase (ASK) Signalosome in Response to 
Electrophile Stress, Mol. Cell. Proteomics, American Society for Biochemistry and Molecular Biology 15, 1947-1961.

29. Croucher, D. R., Iconomou, M., Hastings, J. F., Kennedy, S. P., Han, J. Z. R., Shearer, R. F., McKenna, J., Wan, A., Lau, J., Aparicio, S., and Saunders, D. N. (2016) Bimolecular complementation affinity purification (BiCAP) reveals dimerspecific protein interactions for ERBB2 dimers, Sci. Signal., AAAS 9, ra69-ra69.

30. Hastings, J. F., Han, J. Z. R., Shearer, R. F., Kennedy, S. P., Iconomou, M., Saunders, D. N., and Croucher, D. R. (2018) Dissecting Multi-protein Signaling Complexes by Bimolecular Complementation Affinity Purification (BiCAP), J. Vis. Exp.

31. Yu, Z., Chen, T., Li, X., Yang, M., Tang, S., Zhu, X., Gu, Y., Su, X., Xia, M., Li, W., Zhang, X., Wang, Q., Cao, X., and Wang, J. (2016) Lys29-linkage of ASK1 by Skp1Cullin 1-Fbxo21 ubiquitin ligase complex is required for antiviral innate response, Elife $5,249$.

32. Maruyama, T., Araki, T., Kawarazaki, Y., Naguro, I., Heynen, S., Aza-Blanc, P., Ronai, Z., Matsuzawa, A., and Ichijo, H. (2014) Roquin-2 Promotes UbiquitinMediated Degradation of ASK1 to Regulate Stress Responses, Sci. Signal., AAAS 7, ra8.

33. Rajakulendran, T., Sahmi, M., Kurinov, I., Tyers, M., Therrien, M., and Sicheri, F. (2008) CNK and HYP form a discrete dimer by their SAM domains to mediate RAF kinase signaling, Proc. Natl. Acad. Sci. U. S. A., National Acad Sciences 105, $2836-$ 2841.

34. Wang, Y., Shang, Y., Li, J., Chen, W., Li, G., Wan, J., Liu, W., and Zhang, M. (2018) Specific Eph receptor-cytoplasmic effector signaling mediated by SAM-SAM domain interactions, Elife, eLife Sciences Publications, Ltd 7, e35677.

35. Harada, B. T., Knight, M. J., Imai, S.-I., Qiao, F., Ramachander, R., Sawaya, M. R., Gingery, M., Sakane, F., and Bowie, J. U. (2008) Regulation of enzyme localization by polymerization: polymer formation by the SAM domain of diacylglycerol kinase delta1, Structure, Elsevier Ltd 16, 380-387.

36. Leettola, C. N., Knight, M. J., Cascio, D., Hoffman, S., and Bowie, J. U. (2014) Characterization of the SAM domain of the PKD-related protein ANKS6 and its interaction with ANKS3, BMC Struct. Biol. 14, 17.

37. Lerner, M. G., and Carlson, H. A. (2006) APBS plugin for PyMOL, Ann Arbor: University of Michigan.

38. Jacques, D. A., and Trewhella, J. (2010) Small-angle scattering for structural biology-expanding the frontier while avoiding the pitfalls, Protein Sci. 19,642-657.

39. Good, M. C., Zalatan, J. G., and Lim, W. A. (2011) Scaffold proteins: hubs for controlling the flow of cellular information, Science, American Association for the Advancement of Science 332, 680-686.

40. Coyle, S. M., Flores, J., and Lim, W. A. (2013) Exploitation of Latent Allostery Enables the Evolution of New Modes of MAP Kinase Regulation, Cell, Elsevier Ltd 154, 875887.

41. Bhattacharyya, R. P., Reményi, A., Good, M. C., Bashor, C. J., Falick, A. M., and Lim, W. A. (2006) The Ste5 scaffold allosterically modulates signaling output of the yeast mating pathway, Science, American Association for the Advancement of Science 311, 822-826.

42. Qiao, F., and Bowie, J. U. (2005) The many faces of SAM, Sci. STKE 2005, re7.

43. Knight, M. J., Leettola, C., Gingery, M., Li, H., and Bowie, J. U. (2011) A human sterile alpha motif domain polymerizome, Protein Sci. 20, 1697-1706.

44. Baron, M. K., Boeckers, T. M., Vaida, B., Faham, S., Gingery, M., Sawaya, M. R., Salyer, D., Gundelfinger, E. D., and Bowie, J. U. (2006) An architectural framework that may lie at the core of the postsynaptic density, Science 311, 531-535.

45. Kim, C. A., Phillips, M. L., Kim, W., Gingery, M., Tran, H. H., Robinson, M. A., Faham, S., and Bowie, J. U. (2001) Polymerization of the SAM domain of TEL in leukemogenesis and transcriptional repression, EMBO J. 20, 4173-4182.

46. Koveal, D., Schuh-Nuhfer, N., Ritt, D., Page, R., Morrison, D. K., and Peti, W. (2012) A CC-SAM, for Coiled Coil-Sterile \{alpha\} Motif, Domain Targets the Scaffold KSR-1 to Specific Sites in the Plasma Membrane, Sci. Signal., AAAS 5, ra94-ra94. 
47. Lavoie, H., Sahmi, M., Maisonneuve, P., Marullo, S. A., Thevakumaran, N., Jin, T., Kurinov, I., Sicheri, F., and Therrien, M. (2018) MEK drives BRAF activation through allosteric control of KSR proteins, Nature 554, 549-553.

48. Jarvis, R. M., Hughes, S. M., and Ledgerwood, E. C. (2012) Peroxiredoxin 1 functions as a signal peroxidase to receive, transduce, and transmit peroxide signals in mammalian cells, Free Radic. Biol. Med., Elsevier Inc. 53, 1522-1530.

49. Ledgerwood, E. C., Marshall, J. W. A., and Weijman, J. F. (2017) The role of peroxiredoxin 1 in redox sensing and transducing, Arch. Biochem. Biophys. 617, 6067.

50. Takeda, K., Komuro, Y., Hayakawa, T., Oguchi, H., Ishida, Y., Murakami, S., Noguchi, T., Kinoshita, H., Sekine, Y., lemura, S.-I., Natsume, T., and Ichijo, H. (2009) Mitochondrial phosphoglycerate mutase 5 uses alternate catalytic activity as a protein serine/threonine phosphatase to activate ASK1, Proc. Natl. Acad. Sci. U. S. A. 106, $12301-12305$.

51. Ruiz, K., Thaker, T. M., Agnew, C., Miller-Vedam, L., Trenker, R., Herrera, C., Ingaramo, M., Toso, D., Frost, A., and Jura, N. (2019) Functional role of PGAM5 multimeric assemblies and their polymerization into filaments, Nat. Commun. 10, 531.

52. Chaikuad, A., Filippakopoulos, P., Marcsisin, S. R., Picaud, S., Schröder, M., Sekine, S., Ichijo, H., Engen, J. R., Takeda, K., and Knapp, S. (2017) Structures of PGAM5 Provide Insight into Active Site Plasticity and Multimeric Assembly, Structure 25, 1089-1099.e3.

53. Mace, P. D., and Riedl, S. J. (2010) Molecular cell death platforms and assemblies, Curr. Opin. Cell Biol., Elsevier Ltd 22, 828-836.

54. Filipčík, P., Curry, J. R., and Mace, P. D. (2017) When Worlds Collide-Mechanisms at the Interface between Phosphorylation and Ubiquitination, J. Mol. Biol., Elsevier Ltd 429, 1097-1113.

55. Johannessen, C. M., Boehm, J. S., Kim, S. Y., Thomas, S. R., Wardwell, L., Johnson, L. A., Emery, C. M., Stransky, N., Cogdill, A. P., Barretina, J., Caponigro, G., Hieronymus, H., Murray, R. R., Salehi-Ashtiani, K., Hill, D. E., Vidal, M., Zhao, J. J., Yang, X., Alkan, O., Kim, S., Harris, J. L., Wilson, C. J., Myer, V. E., Finan, P. M., Root, D. E., Roberts, T. M., Golub, T., Flaherty, K. T., Dummer, R., Weber, B. L., Sellers, W. R., Schlegel, R., Wargo, J. A., Hahn, W. C., and Garraway, L. A. (2010) COT drives resistance to RAF inhibition through MAP kinase pathway reactivation, Nature 468, 968-972.

56. Panjikar, S., Parthasarathy, V., Lamzin, V. S., Weiss, M. S., and Tucker, P. A. (2005) Auto-rickshaw: an automated crystal structure determination platform as an efficient tool for the validation of an X-ray diffraction experiment, Acta Crystallogr. D Biol. Crystallogr., International Union of Crystallography 61, 449-457.

57. Joosten, R. P., Long, F., Murshudov, G. N., and Perrakis, A. (2014) The PDB_REDO server for macromolecular structure model optimization, IUCrJ, International Unnion of Crystallography 1, 213-220.

58. Adams, P. D., Afonine, P. V., Bunkóczi, G., Chen, V. B., Echols, N., Headd, J. J., Hung, L.-W., Jain, S., Kapral, G. J., Grosse-Kunstleve, R. W., McCoy, A. J., Moriarty, N. W., Oeffner, R. D., Read, R. J., Richardson, D. C., Richardson, J. S., Terwilliger, T. C., and Zwart, P. H. (2011) The Phenix software for automated determination of macromolecular structures, Methods 55, 94-106.

59. Emsley, P., and Cowtan, K. (2004) Coot: model-building tools for molecular graphics, Acta Crystallogr. D Biol. Crystallogr., International Union of Crystallography 60, 21262132.

60. Kirby, N. M., Mudie, S. T., Hawley, A. M., Cookson, D. J., Mertens, H. D. T., Cowieson, N., and Samardzic-Boban, V. (2013) A low-background-intensity focusing small-angle X-ray scattering undulator beamline, J. Appl. Crystallogr., International Union of Crystallography 46, 1670-1680.

61. Foglizzo, M., Middleton, A. J., Burgess, A. E., Crowther, J. M., Dobson, R. C. J., Murphy, J. M., Day, C. L., and Mace, P. D. (2018) A bidentate Polycomb RepressiveDeubiquitinase complex is required for efficient activity on nucleosomes, Nat.

Commun. 9, 3932. 
62. Petrie, E. J., Sandow, J. J., Jacobsen, A. V., Smith, B. J., Griffin, M. D. W., Lucet, I. S., Dai, W., Young, S. N., Tanzer, M. C., Wardak, A., Liang, L.-Y., Cowan, A. D., Hildebrand, J. M., Kersten, W. J. A., Lessene, G., Silke, J., Czabotar, P. E., Webb, A. I., and Murphy, J. M. (2018) Conformational switching of the pseudokinase domain promotes human MLKL tetramerization and cell death by necroptosis, Nat. Commun. $9,2422$.

63. Kirby, N., Cowieson, N., Hawley, A. M., Mudie, S. T., McGillivray, D. J., Kusel, M., Samardzic-Boban, V., and Ryan, T. M. (2016) Improved radiation dose efficiency in solution SAXS using a sheath flow sample environment, Acta crystallographica. Section D, Structural biology, International Union of Crystallography 72, 1254-1266.

64. Konarev, P. V., Volkov, V. V., Sokolova, A. V., Koch, M. H. J., and Svergun, D. I. (2003) PRIMUS: a Windows PC-based system for small-angle scattering data analysis, J. Appl. Crystallogr., International Union of Crystallography 36, 1277-1282.

65. Svergun, D. I. (1992) Determination of the regularization parameter in indirecttransform methods using perceptual criteria, J. Appl. Crystallogr., International Union of Crystallography 25, 495-503.

66. Svergun, D., Barberato, C., and Koch, M. H. J. (1995) CRYSOL - a Program to Evaluate X-ray Solution Scattering of Biological Macromolecules from Atomic Coordinates, J. Appl. Crystallogr., International Union of Crystallography 28, 768-773.

67. Franke, D., Petoukhov, M. V., Konarev, P. V., Panjkovich, A., Tuukkanen, A., Mertens, H. D. T., Kikhney, A. G., Hajizadeh, N. R., Franklin, J. M., Jeffries, C. M., and Svergun, D. I. (2017) ATSAS 2.8: a comprehensive data analysis suite for smallangle scattering from macromolecular solutions, J. Appl. Crystallogr. 50, 1212-1225. 